\title{
Testando as Previsóes de Trade-offe Pecking Order sobre Dividendos e Dívida no Brasil
}

Júlio Cesar G. da Silva Ricardo D. Brito
Faculdades Ibmec/RJ

Ibmec São Paulo

\section{RESUMO}

Este trabalho mostra que as companhias brasileiras distribuem uma proporção pequena dos lucros em dividendos apesar da legislação favorável. Os dividendos pagos são rapidamente ajustados ao lucro corrente, mas parte da variação de curto prazo nos lucros é absorvida por dívida. De acordo com a previsão comum dos modelos de trade-off e pecking order, as firmas mais lucrativas e menos endividadas distribuem uma maior proporção. Ainda de acordo com a pecking order, os dividendos não sofrem variações de curto prazo para acomodar os investimentos. Finalmente, as firmas mais lucrativas e que menos investem são as menos endividadas, favorecendo a pecking order contra trade-off.

\section{PALAVRAS-CHAVE}

dividendos, dívida, trade-off, pecking order, Brasil

ABSTRACT

This article shows that the Brazilian companies have a low target payout ratio, although the local tax code favors dividends' distributions. The dividends paid present fast adjustment to current earnings, but part of the short-term variation in earnings is still absorbed by debt. Confirming predictions shared by the trade-off and pecking order models, more profitable firms and less levered firms have higher dividend payouts. Consistent with the pecking order model, dividends do not vary in the short-term to accommodate investments. Finally, more profitable firms and firms with fewer investments are less levered, accepting the pecking order hypothesis against the trade-off one.

KEY WORDS

dividends, debt, trade-off, pecking order, Brazil

JEL Classification

G32, G35 


\section{INTRODUÇÃO}

Este trabalho tem como objetivo testar as previsões das teorias de trade-off $\mathrm{e}$ pecking order sobre dividendos e dívida. Sendo estes dois modelos derivados de hipóteses distintas, divergem em algumas previsões sobre as políticas ótimas de dividendos e dívida, e possibilitam testes empíricos em que uma teoria é a hipótese alternativa à outra. Modelando dividendos e dívida conjuntamente é possível verificar sua interdependência, examinar como variam em função da lucratividade e dos investimentos, bem como testar se revertem para alguma meta ou se respondem permanentemente às variações de caixa.

Estudo semelhante, no qual este trabalho se baseia, foi realizado com dados de empresas norte-americanas por Fama e French (2002). Como apresentado na Tabela 1 abaixo, estes autores verificam a correção das previsões comuns a trade-off e pecking order. Entretanto, não concluem pela razão de uma contra a outra, dado que os resultados obtidos alternam entre favoráveis a trade-off ou a pecking order nos casos de previsões divergentes.

TABELA 1 - RESUMO DOS RESULTADOS DE FAMA E FRENCH (2002)

\begin{tabular}{lcc}
\hline RESULTADO OBTIDO EM FAMA E FRENCH (2002) & $\begin{array}{c}\text { Favorece } \\
\text { Trade-off? }\end{array}$ & $\begin{array}{c}\text { Favorece } \\
\text { Pecking } \\
\text { order? }\end{array}$ \\
\hline Firmas mais lucrativas distribuem mais dividendos & Sim & Sim \\
Firmas com poucas oportunidades de investimentos distribuem mais dividendos & Sim & Sim \\
As firmas maiores e de resultados menos voláteis distribuem mais dividendos & Sim & Sim \\
As firmas mais lucrativas se endividam mais & Não & Sim \\
As firmas com maiores oportunidades de investimentos são menos endividadas & Sim & Não \\
As firmas mais endividadas distribuem menos dividendos & Sim & Sim \\
Dividendos não sofrem variações de curto prazo para acomodar os investimentos & Não & Sim \\
Variações de curto prazo nos lucros e nos investimentos são absorvidas por dívida & Não & Sim \\
\hline
\end{tabular}


Existem inúmeros trabalhos empíricos que objetivam esclarecer quais são os fatores determinantes da estrutura de capital, cabendo citar Titman e Wessels (1988) e Rajan e Zingales (1995) com dados internacionais, Brito e Lima (2005), Perobelli e Famá (2002) e Gomes e Leal (2001) com dados brasileiros. Porém, poucos trabalhos como Jalilvand e Harris (1984) e Auerbach (1985) testaram se dívida reverte à média, conforme sustenta a previsão do modelo de trade-off, e apenas Shyam-Sunder e Myers (1999) testam a resposta da dívida às variaçóes de curto prazo dos investimentos e da lucratividade.

Poucos estudos a respeito dos fatores determinantes da política de dividendos são encontrados na literatura. Para o mercado americano, podemos citar Fama e French (2002) como o mais completo sobre o assunto. Para o mercado brasileiro, noutro contexto, Procianoy e Verdi (2001) testaram a existência do efeito clientela devido às diferenças entre as alíquotas de impostos pagas pelas pessoas físicas. Já Figueiredo (2002) testou a validade da hipótese de que os dividendos possuem conteúdo informacional, sendo utilizado pelo gestor como forma de sinalizar a boa situação da empresa.

Até onde conhecemos, este é o primeiro estudo brasileiro a testar as previsões das teorias de trade-off e pecking order sobre dividendos e também o primeiro a modelar conjuntamente dívida e dividendos, examinando suas interações.

A maioria dos trabalhos empíricos que estudaram os fatores determinantes da estrutura de capital das empresas utilizou regressóes do tipo seccional ou painel. Como apontado por Fama e French (2002), ambas as técnicas ignoram problemas de correlação que podem enviesar os resultados. Quando regressões seccionais são utilizadas, ignora-se a correlação dos resíduos entre as firmas. Já em regressões de painel simples, ignora-se tanto o problema de correlação seccional quanto o problema de viés dos erros padrões dos coeficientes estimados devido à correlação temporal das medidas seccionais. Como sugerido por Fama e French (2002), este trabalho utiliza o método de Fama e McBeth (1973), robusto à correlação seccional, e indica um ajuste dos erros padróes para a autocorrelação dos coeficientes. 
Os resultados mostram que a proporção dos lucros distribuída como dividendos no Brasil é inferior à americana, apesar da legislação brasileira favorável. Os dividendos pagos se ajustam parcialmente ao lucro corrente, mas o ajuste é relativamente rápido. De acordo com a previsão comum dos modelos de trade-offe pecking order, as firmas mais lucrativas e menos endividadas distribuem uma maior proporção, apesar da proporção distribuída não se mostrar sensível ao investimento. Ainda de acordo com a pecking order, os dividendos pagos não sofrem ajustes de curto prazo para acomodar os investimentos. Finalmente, as firmas mais lucrativas e que menos investem são as menos endividadas, favorecendo a pecking order contra trade-off, e parte da variação de curto prazo nos lucros é absorvida por dívida.

Além desta introdução, na seção seguinte abordamos os modelos de decisões de financiamento e remuneração. Na seção 2 definimos as proxies utilizadas neste estudo. Na seção 3 descrevemos os dados coletados e seus critérios de escolha, bem como a abordagem de estimação. Nas seções 4 a 7 analisamos os resultados das regressões de dividendos e dívida. Por fim, na última seção apresentaremos as conclusões e considerações finais.

\section{MODELOS DE DECISÕES DE FINANCIAMENTO E REMUNERAÇÃO}

As extensas literaturas de políticas de financiamento e de remuneração encontram-se competentemente resumidas em artigos como Harris e Raviv (1991) e Allen e Michaely (2003), referências para o leitor interessado numa apresentação mais detalhada. Finalmente, favorecendo pecking order contra trade-off, as firmas mais lucrativas e que menos investem são as menos endividadas, sendo parte da variação de curto prazo nos lucros absorvida por dívida. 
TABELA 2 - SINAL DA RELAÇ̃̃O ESPERADA ENTRE AS VARIÁVEIS SEGUNDO AS TEORIAS DE TRADE-OFF E PECKING ORDER

\begin{tabular}{|c|c|c|c|c|c|}
\hline \multirow[b]{2}{*}{ Fatores } & \multirow[b]{2}{*}{ Proxies } & \multicolumn{2}{|c|}{ TRADE-OFF } & \multicolumn{2}{|c|}{ PECKING ORDER } \\
\hline & & Dívida & Dividendos & Dívida & Dividendos \\
\hline Lucratividade & $E_{t} / A_{t}, E T_{t} / A_{t}, V_{t} / A_{t}$ & + & + & - & + \\
\hline Investimento & $V_{t} / A_{t}, d A_{t} / A_{t}$ & - & - & + & - \\
\hline Tamanho & $\operatorname{LN}\left(A_{t}\right)$ & + & + & + & + \\
\hline Meta de Dividendo & $\mathrm{TP}_{\mathrm{t}+1}$ & - & & - & \\
\hline Meta de Alavancagem & $\mathrm{TL}_{\mathrm{t}+1}$ & & - & & - \\
\hline
\end{tabular}

\subsection{O Modelo de Trade-off}

O modelo de trade-off considera imperfeições de mercado como os custos de insolvência, impostos e problemas de agência criados pelo conflito de interesses entre acionistas e controladores ou credores. Neste contexto, a estrutura de capital e a política de dividendos são utilizadas para minimizar os custos gerados pelas imperfeições. As firmas maximizam seu valor ao escolherem aqueles níveis de dívida e dividendos que igualam os custos marginais aos benefícios marginais dessas ações. Para dívida, por exemplo, o maior custo é o de insolvência, o qual aumenta significativamente quando há uma diminuição da lucratividade e aumento da volatilidade dos lucros. Já os benefícios são alcançados com a possibilidade de dedução de impostos.

Nos modelos de agência proposto por Jensen e Meckling (1976), Easterbrook (1984) e Jensen (1986) existem dois tipos de conflitos. O conflito entre acionista e diretor proprietário, surge quando o diretor proprietário não possui $100 \%$ das ações da empresa. Quanto menos dono do negócio for o diretor, maior será o incentivo em aumentar seus gastos não-produtivos, pois estará arcando com uma menor porção deste custo e se beneficiando integralmente. O acionista, por sua vez, age racionalmente se 
antecipando ao comportamento do diretor e descontando o valor da firma. Para minimizar tal custo de agência, o diretor proprietário tem que aceitar controles externos, como auditoria, restrições orçamentárias e compensação por resultados, que resultam em custos de agência de abertura do capital.

Outro conflito observado é o existente entre os acionistas e credores, que surge porque os contratos são incompletos e incentivam os acionistas a não investirem otimamente. A partir deste conflito os autores observaram dois tipos de custos de agência da dívida: investimento exagerado e investimento insuficiente. O custo do investimento exagerado se efetiva quando uma firma muito endividada efetua um investimento arriscado com valor presente líquido esperado negativo. Neste caso, se o projeto tem sucesso os acionistas recebem maior parte dos lucros. Se fracassar, os credores arcam com as maiores perdas. Os credores se antecipam a esta possibilidade e incorporam o custo esperado à taxa cobrada pelo financiamento, o que reduz o valor residual dos acionistas. Este efeito é denominado efeito substituição de ativos. As firmas mais maduras têm maior probabilidade de investir exageradamente. Já o custo de investimento insuficiente se origina quando as firmas estão insolventes. Neste caso, alguns projetos com valor presente líquido esperado positivo serão desprezados, pois os acionistas, que têm apenas o retorno residual, preferirão não fazê-lo. Novamente, os credores antecipam essas possibilidades e cobram pelo empréstimo mais do que na situação onde tais riscos não existem (efeito substituição dos ativos). As firmas com as maiores oportunidades de crescimento possuem maior probabilidade de investir insuficientemente.

\subsubsection{Trade-off e Dividendos}

Problemas como assimetria da informação e outros custos de financiamento fortalecem as previsões do modelo de trade-off sobre dividendos. Neste modelo, as firmas que pagam mais dividendos devem ser as mais lucrativas. $\mathrm{O}$ motivo desta relação é diminuir o excesso de caixa livre e as possibilidades de gastos não-produtivos pela gerência (perigo moral). As empresas que pagam mais dividendos também são as de menores oportunidades de investimento, visto que as firmas que investem mais já têm uma destinação para os seus resultados. Ainda pelo mesmo argumento, às empresas menos alavanca- 
das resta pagar mais dividendos como alternativa para diminuir o excesso de caixa livre. Finalmente, as empresas que possuem maior volatilidade em seus lucros deverão destinar menos recursos para dividendos devido à incerteza associada a lucros futuros.

Quanto à economia de impostos, nos EUA os impostos pagos pelas pessoas físicas são maiores para dividendos do que para ganhos de capital. Logo, os acionistas obtêm maior lucro por meio da recompra das ações via dividendos e, deste modo, é ótimo minimizar os dividendos. Fama e French (2001) e Allen e Michaely (2003) mostraram que as empresas norte-americanas, a partir dos anos 80, diminuíram a distribuição dos lucros via pagamento de dividendos e aumentaram a parcela de recompra de ações, modificando, assim, a forma como remunera seus acionistas.

No caso do Brasil, diferentemente dos EUA, dividendos e juros sobre o capital próprio são alternativas para economizar impostos. Isso porque atualmente é de $20 \%$ a alíquota sobre os ganhos de capital em operações de renda variável e de $0 \%$ a alíquota para dividendos recebidos. ${ }^{1}$ Além disso, a legislação brasileira permite que parte dos dividendos, na forma de juros sobre o capital próprio, seja considerada como despesa financeira, reduzindo a base de cálculo do imposto de renda e contribuição social sobre o lucro líquido, montante que pode chegar a $34 \%$ do lucro tributável. Ou seja, tudo mais constante, espera-se que no Brasil seja ótimo pagar dividendos e não recomprar ações. Para simplificar a notação, daqui ao final do trabalho, quando abordarmos a palavra dividendos estaremos supondo que os juros sobre o capital próprio estão embutidos nesta conta.

\subsubsection{Trade-off e Dívida}

De Angelo e Masulis (1980) mostram que a irrelevância da alavancagem da firma de Miller (1977) é sensível a adaptações realistas, como a inclusão de

1 Lei no 9.249, de 26 de dezembro de 1995, em vigor a partir de 1996. Antes de 1995, a diferença foi favorável ao pagamento de dividendos na maioria dos anos. No período 1990-93, a legislação tributária brasileira definia uma alíquota de $0 \%$ sobre os dividendos recebidos e $25 \%$ sobre ganhos de capital. No ano de 1994, as alíquotas foram de $15 \%$ sobre os dividendos e $25 \%$ sobre ganhos de capital. Apenas no ano de 1995, o ganho de capital foi menos tributado que os dividendos, com alíquotas de respectivamente $10 \%$ e $15 \%$. 
custos de falência, monitoramento e outros custos individuais decorrentes do financiamento por dívida. Pelo fato de o custo de insolvência ser menor para empresas com maior valor de liquidação, empresas com maior proporção de ativos tangíveis tendem a utilizar relativamente mais dívida. Da mesma forma, empresas maiores, em geral mais antigas, diversificadas e transparentes, têm menor probabilidade de falência e custo de monitoramento, devendo apresentar maior razão de endividamento. E ainda firmas mais lucrativas ou menos voláteis devem ser mais endividadas, pois possuem menores custos esperados de falência.

Dado que a divisão assimétrica da firma cria oportunidades de aumento do valor de um grupo à custa de outro, muitas vezes com redução do valor total do negócio, utiliza-se a estrutura de capital para minimizar tais conflitos. Entre seus benefícios, o endividamento contribui para que o gerente se empenhe em maximizar o valor da empresa, à medida que aumenta sua participação relativa na mesma e em seus lucros, além de reduzir os fluxos de caixa livres passíveis de destinação não-produtiva. Pelo lado dos custos, a alavancagem causa o efeito substituição do ativo. Da compensação entre benefícios e custos da dívida resulta que as empresas mais lucrativas devem apresentar maior nível de endividamento, e aquelas sujeitas a maior efeito substituição do ativo devem apresentar menor nível de endividamento. Em geral, empresas com maiores oportunidades de investimento correm maior risco de investimento insuficiente e devem apresentar menor nível de endividamento. Por outro lado, quanto mais restritas as oportunidades de investimento, maior o risco de investimento exagerado e maior o nível de endividamento indicado.

\subsection{O Modelo de Pecking Order}

Este modelo foi proposto por Myers (1984) e Myers e Majluf (1984), os quais mostram como a assimetria de informação influencia nas decisões de financiamento das empresas. A motivação para este estudo é que os gerentes usam informações privilegiadas para se financiarem com ativos arriscados quando a firma está valorizada. Como os financiadores são racionais, eles antecipam esta ação e descontam o valor da firma quando ativos arriscados 
são utilizados para implementação de novos projetos. Assim, o financiamento por estes meios é interpretado pelo mercado como uma má notícia, e na data do anúncio da emissão, o valor de mercado das antigas ações cai. Os gerentes também antecipam este desconto e, por isso, não implementarão alguns investimentos com valor presente líquido maior que zero se não possuírem recursos em caixa, uma vez que causariam perda de capital para os sócios atuais.

Logo, para minimizar os custos desta assimetria de informação, as firmas financiam seus investimentos seguindo uma ordem hierárquica de recursos: recursos próprios, títulos sem risco, títulos arriscados e, por último, emitindo novas ações.

\subsubsection{Pecking Order e Dividendos}

Apesar do modelo de pecking order não explicar os motivos que levam as firmas a distribuírem dividendos aos seus acionistas, as considerações desta teoria devem afetar tais decisões quando as empresas decidem distribuí-los.

Devido à existência da assimetria informacional descrita na subseção anterior e à ordem hierárquica de obtenção de recursos para financiamento de novos projetos, podemos dizer que financiar investimentos com ativos arriscados é caro e muitas vezes não deverão ser implementados. Logo, dividendos são menos atrativos para firmas com pouca lucratividade, pois estarão abrindo mão de recursos próprios para financiar projetos. Firmas com maior expectativa de investimentos deverão pagar menos dividendos.

Por outro lado, alto nível de alavancagem é esperado para firmas que pagam menos dividendos. Segundo a pecking order, dividendos deverão ser pagos pelas empresas mais lucrativas. Então, quanto menos endividada for a empresa, maior será o seu lucro e por isso uma maior quantia deverá ser distribuída aos acionistas em forma de dividendos.

E, por fim, grande volatilidade do lucro significa dividendos menores, pois firmas com lucros variáveis têm mais chance de precisarem recorrer 
ao financiamento externo, ou variar os dividendos, quando os lucros forem baixos.

\subsubsection{Pecking Order e Dívida}

Como no mundo de Myers (1984) os custos de emissão de novos títulos dominam as forças de trade-off, as variações do nível de dívida passam a ser determinadas pela diferença entre investimentos e lucros. A empresa financiará seus projetos preferencialmente com recursos próprios, esperando-se que o endividamento decresça quando investimentos não excedem os lucros. Há uma relação positiva entre dívida e investimentos e uma relação negativa entre dívida e lucratividade.

Como no modelo de trade-off, prevê-se uma relação positiva entre tamanho e endividamento. Para diminuir a probabilidade de se financiar via ativos arriscados ou emissão de novas ações, as empresas com maior volatilidade em seus fluxos se endividarão menos.

\section{PROXIES UTILIZADAS E RELAÇÕES ESPERADAS}

Descreveremos nesta seção as proxies utilizadas no trabalho, relacionando-as com as teorias de decisões de financiamento e remuneração apresentadas na seção anterior. Nossas medidas de lucratividade, oportunidades de investimento e risco são as mesmas de Fama e French (2002).

\subsection{Expectativa de Lucratividade $\left(E_{t} / A_{t} e E T_{t} / A_{t}\right)$}

Usamos $\mathrm{E}_{\mathrm{t}} / \mathrm{A}_{\mathrm{t}}$, a razão do lucro antes do imposto de renda pelo ativo total em valor contábil, como medida para expectativa de lucratividade. Já $\mathrm{ET}_{\mathrm{t}}$ / $\mathrm{A}_{\mathrm{t}}$ é definida como a razão entre o lucro operacional próprio pelo ativo total em valor contábil, que difere da primeira por levar em conta os efeitos dos impostos, relevantes no modelo de trade-off.

A teoria da pecking order afirma que, dado o investimento constante, firmas com maiores expectativas de lucros futuros devem apresentar maiores paga- 
mentos de dividendos, pois pagarão estes dividendos com seus próprios recursos sem precisarem se financiar externamente. A mesma relação positiva é esperada pela teoria de trade-off, na qual, visando diminuir os problemas de caixa livre, as firmas pagarão parte dos lucros em dividendos. Logo, é esperada uma relação positiva entre dividendos e lucratividade.

Quando analisamos a dívida como variável dependente, notamos previsóes opostas segundo as teorias. Para o modelo de trade-off, as firmas mais lucrativas devem ser as mais alavancadas, diminuindo o excesso de caixa livre. $\mathrm{O}$ contrário espera-se pela teoria da pecking order, uma vez que as firmas mais lucrativas deverão evitar os elevados custos do financiamento externo, sendo, por este motivo, menos alavancadas.

\subsection{Oportunidades de Investimento $\left(V_{t} / A_{t} e d A_{t} / A_{t}\right)$}

Uma proxy para oportunidades esperadas de investimento é $V_{t} / A_{t}$, a razão entre o valor de mercado da firma e o valor contábil do ativo total, muitas vezes denominada $Q$ de Tobin. Segundo Tobin (1969), como o valor de mercado, $V_{t}$, deve refletir o valor presente dos lucros esperados do capital instalado, e o valor contábil, $A_{t}$, é uma aproximação do custo de reprodução deste capital, são tão melhores as oportunidades de investimento quanto maior a razão $V_{t} / A_{t}$. Ou seja, vale a pena investir se os lucros esperados superam o custo do investimento. Embora $V_{t} / A_{t}$ seja a priori uma medida de investimentos futuros, também pode carregar informações sobre lucratividade corrente. Uma medida direta de investimento corrente é a variação porcentual do ativo total, $\left(d A_{t} / A_{t}\right)$, que se o investimento for persistente, pode servir também como proxy para a expectativa de oportunidades de investimento.

Podemos dizer que se lucratividade é constante, firmas com maiores investimentos têm menor pagamento de dividendos. Como se financiar via financiamento externo é caro (pecking order) e diminuir os gastos não-produtivos com o gerente é preciso (trade-off), as firmas deverão utilizar grande parte dos recursos disponíveis em investimentos, diminuindo os recursos para pa- 
gamentos de dividendos. Logo, a relação esperada entre dividendos e investimentos deve ser negativa segundo ambas as teorias.

Novamente uma discordância entre as teorias é observada quando analisamos a relação esperada entre o endividamento das empresas e os investimentos. Segundo o modelo de trade-off, as empresas que mais investem devem ser as menos alavancadas, seja para evitar o problema de investimento insuficiente, seja porque o investimento oferece uma alternativa à dívida para reduzir o excesso de caixa livre. Contrariamente, a pecking order prevê relação positiva, uma vez que investimentos maiores tendem a exceder os recursos próprios com maior freqüência, devendo ser financiados por dívida.

\subsection{Medida de Volatilidade $\left(\ln \left(A_{t}\right)\right)$}

Segundo Fama e French (2002), as firmas com maiores ativos totais são mais sólidas e, por isso, devem apresentar menor volatilidade em seus ganhos e em seu fluxo de caixa líquido. Por este motivo utilizamos o logaritmo neperiano do ativo total como medida de tamanho, a qual refletirá a hipótese de menor volatilidade dos resultados das empresas. Nos dois modelos estudados a relação esperada deve ser positiva, ou seja, firmas maiores devem apresentar menos volatilidade e, por isso, devem pagar mais dividendos e se alavancar mais.

\subsection{Medidas para Meta de Alavancagem $\left(T L_{t+1}\right)$ e Meta de Remuneração $\left(T P_{t+1}\right)$}

A meta de alavancagem, $T L_{t+1}$, será o valor estimado da regressão de alavancagem na forma reduzida (conforme equação (6.1) adiante). Já $T P_{t+1}$ é a meta para a taxa de remuneração dos acionistas, e seus valores serão estimados a partir da regressão de dividendos na forma reduzida (conforme equação (4.3) adiante).

Espera-se uma relação negativa entre alavancagem e dividendos pelas duas teorias. Isto porque na teoria de trade-off dívida e dividendos são alternativas para alocar os recursos livres, minimizando os problemas de perigo moral da gerência. Na teoria de pecking order, empresas mais endividadas têm 
uma maior parcela dos seus recursos internos comprometidos com serviços de dívida e um menor resíduo para o pagamento de dividendos.

\section{DADOS E PROCEDIMENTO DE ESTIMAÇÃO}

Este estudo utiliza os demonstrativos contábeis consolidados disponíveis na base Economática para 111 empresas brasileiras não-financeiras de capital aberto durante os anos de 1995 a 2001, devidamente corrigidos pela inflação do IGP-DI da Fundação Getúlio Vargas (listadas no Apêndice A).

As empresas foram selecionadas pelos seguintes critérios: (i) companhias que apresentaram dados completos no período da análise, e (ii) firmas que pagaram dividendos pelo menos uma vez durante o intervalo do estudo. $\mathrm{O}$ Gráfico 1 apresenta o número de anos que as 111 empresas analisadas pagaram dividendos durante o período de 7 anos.

GRÁFICO I - NÚMERO DE ANOS EM QUE AS EMPRESAS PAGARAM DIVIDENDOS DURANTE OS 7 ANOS DE ANÁLISE

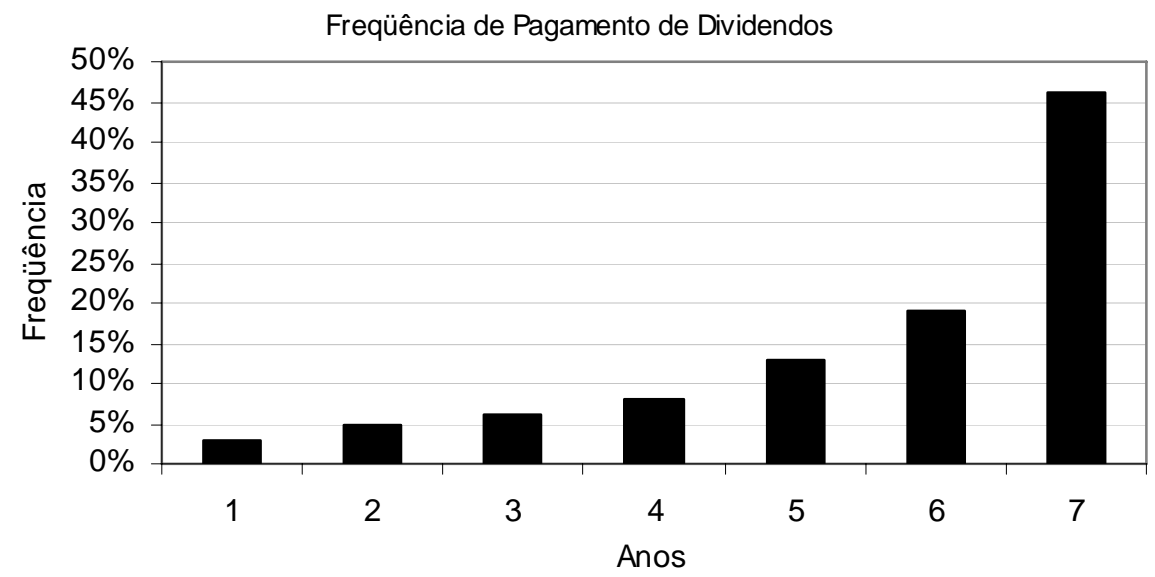


A Tabela 3.1 apresenta a média e mediana da razão dividendos sobre lucro líquido para todo o período (linha Total) e para cada ano. Observa-se que esta razão tem suas medidas de tendência central próximas a $20 \%$. Já na Tabela 3.2 encontram-se as médias e medianas anuais da razão do endividamento total sobre ativo total em valor contábil. As estimativas de tendência central estão em torno de $\mathbf{5 0 \%}$.

TABELA 3.1 - MÉDIAS E MEDIANAS DA RAZÃO DOS DIVIDENDOS SOBRE O LUCRO LÍQUIDO

\begin{tabular}{lccc}
\hline Ano & Média & Mediana & № de empresas pagadoras \\
\hline 1995 & 0,30 & 0,23 & 88 \\
1996 & 0,34 & 0,18 & 86 \\
1997 & 0,29 & 0,19 & 89 \\
1998 & 0,20 & 0,13 & 90 \\
1999 & 0,24 & 0,11 & 88 \\
2000 & 0,21 & 0,20 & 89 \\
2001 & 0,16 & 0,24 & 89 \\
\hline Total & 0,25 & 0,18 & 619 \\
\hline
\end{tabular}

Reporta as médias e medianas anuais e total da razão dos dividendos sobre o lucro líquido $\left(D_{t} / Y_{t}\right)$. Excluímos da amostra as empresas 31 e 58 em 2000 e a empresa 68 em 2001 por apresentarem valores que distorciam a média. Ou seja, as medidas assumem um total de 774 elementos, sendo 108 em 2000, 109 em 2001 e 110 nos outros anos. Por exemplo, a média do total é $\left[\sum_{i, t}\left(\begin{array}{c}D_{i t} / Y_{i t} \\ )\end{array}\right) / 774\right.$ e a mediana do total é o ponto médio das 774 observações. 
TABELA 3.2 - MÉDIAS E MEDIANAS DA RAZÃO DO ENDIVIDAMENTO TOTAL CONTÁBIL SOBRE O ATIVO TOTAL

\begin{tabular}{lcc}
\hline Ano & Média & Mediana \\
\hline 1995 & 0,39 & 0,37 \\
1996 & 0,48 & 0,45 \\
1997 & 0,53 & 0,50 \\
1998 & 0,54 & 0,50 \\
1999 & 0,57 & 0,55 \\
2000 & 0,56 & 0,58 \\
2001 & 0,60 & 0,59 \\
\hline Total & 0,53 & 0,51 \\
\hline
\end{tabular}

Reporta as médias e medianas anuais e total da razão do endividamento total em valor contábil, calculado como a soma do passivo circulante com o exigível de longo prazo, sobre $\mathrm{o}$ ativo total em valor contábil para o ano $\mathrm{t},\left(\mathrm{L}_{\mathrm{t}} / \mathrm{A}_{\mathrm{t}}\right)$. As medidas assumem um total de 777 elementos, sendo 110 em cada um dos anos. Por exemplo, a média do total é $\left[\sum_{i, t}\left(L_{i t} / A_{i t}\right)\right] / 777$ e a mediana do total é o ponto médio das 777 observações.

Porque, segundo as teorias de trade-off e pecking order, tanto dividendos quanto dívida são funções das variáveis exógenas lucratividade, oportunidades de investimento e volatilidade, as regressões seguintes consideram essas duas variáveis como endógenas. Considerando-se ainda que o nível desejado de dividendos depende do nível desejado de alavancagem e vice-versa, primeiramente estimamos as equações em suas formas reduzidas para eliminarmos os problemas de endogeneidade. Também modelamos as equações de ajustamento que capturam se dividendos e alavancagem tendem às respectivas metas.

Utilizamos a abordagem de Fama e McBeth (1973), como sugerido em Fama e French (2002), que reporta as médias dos coeficientes de inclinação anuais estimados a partir de regressões seccionais. Para inferir as significâncias, calculam-se estatísticas t de Student pela divisão de cada coeficiente médio por seu desvio padrão amostral. A principal vantagem deste método 
é a correção da correlação seccional existente tanto em regressôes seccionais quanto em painel. Além disto, o método de Fama e McBeth também é robusto à heteroscedasticidade, visto que não existe correção para heteroscedasticidade em uma amostra de médias. ${ }^{2}$ Devido ao problema da autocorrelação, indica-se a correção do valor crítico sob a hipótese dos coeficientes estimados serem processos auto-regressivos de ordem $1(A R(1))$. Por exemplo, tomando a postura conservadora de autocorrelação do coeficiente igual a $\rho=0,6$, deve-se multiplicar o valor crítico por $2:^{3}$

$$
\sigma^{2}\left(\sum_{t=1}^{T} \lambda_{t}\right) \cong T \sigma^{2}(\lambda)+2 \sigma^{2}(\lambda) T \frac{\rho}{1-\rho}
$$

e assumindo $\rho=0,6$, tem-se $\sigma^{2}\left(\sum_{t=1}^{T} \lambda_{t}\right) \cong 4 T \sigma^{2}(\lambda)$, ou $\sigma(\hat{\lambda})=2 \sigma(\bar{\lambda})$, onde $\bar{\lambda}$ é a média de $\lambda_{t}$ s não-correlacionados.

Para efeito de comparação, todas as equações do trabalho também encontram-se reestimadas por painel, com dummies anuais para minimizar a correlação seccional, no Apêndice D.

\section{DETERMINANTES DOS DIVIDENDOS}

Fama e French (2002) e Allen e Michaely (2003) argumentam que o modelo usado por Lintner (1956) descreve bem o comportamento dos dividendos. Este autor enumera três características importantes da política de dividendos. A primeira é que as firmas se preocupam com a estabilidade dos dividendos, pois os gerentes acreditam que o mercado premia as firmas que

2 Ver COCHRANE (2001, cap. 12), para uma apresentação mais detalhada do procedimento de Fama-McBeth.

3 Sob a hipótese de $\lambda_{t}$ ser um $A R(1)$, com variância $\sigma^{2}(\lambda)$ e autocorrelação $\rho$, a variância da soma da seqüência de $T$ observações é igual a: $\sigma^{2}\left(\sum_{t=1}^{T} \lambda_{t}\right)=T \sigma^{2}(\lambda)+2 \sigma^{2}(\lambda) \sum_{t=1}^{T-1} \sum_{j=t+1}^{T} \rho^{j-t}$, que para um $T$ grande, pode ser aproximada por: $\sigma^{2}\left(\sum_{t=1}^{T} \lambda_{t}\right) \cong T \sigma^{2}(\lambda)+2 \sigma^{2}(\lambda) T \frac{\rho}{1-\rho}$; e assumindo $\rho=0,6$, tem-se $\sigma^{2}\left(\sum_{t=1}^{T} \lambda_{t}\right) \cong 4 T \sigma^{2}(\lambda)$, ou $\sigma(\hat{\lambda})=2 \sigma(\bar{\lambda})$, onde $\bar{\lambda}$ é a média de $\lambda_{t}$ s não-correlacionados. 
estabilizam os dividendos. A segunda observação é que o lucro é o determinante mais importante de qualquer mudança nos dividendos e que as companhias possuem metas de longo prazo de distribuição dos lucros. E a terceira diz que os gerentes decidem a política de dividendos antes, planejando outras políticas a partir da análise dos dividendos. Por isso, Lintner concluiu que a distribuição de dividendos é suave ao longo do tempo, tendendo a aumentar após elevações permanentes dos lucros, por ajustes graduais. Ou seja, a política de dividendos pode ser descrita pelo seguinte modelo:

$$
\begin{aligned}
& \mathrm{TD}_{\mathrm{t}+1}=\mathrm{TP}^{*} \mathrm{Y}_{\mathrm{t}+\mathrm{l}} \\
& \mathrm{D}_{\mathrm{t}+1}-\mathrm{D}_{\mathrm{t}}=\operatorname{SOA}\left(\mathrm{TD}_{\mathrm{t}+1}-\mathrm{D}_{\mathrm{t}}\right)+\mathrm{u}_{\mathrm{t}+1}
\end{aligned}
$$

onde:

$\mathrm{TD}_{\mathrm{t}+1}=$ meta de dividendos no ano $\mathrm{t}+\mathrm{l}$;

$\mathrm{Y}_{\mathrm{t}+1}=$ lucro líquido em $\mathrm{t}+\mathrm{l}$;

$\mathrm{TP}=$ meta de longo prazo para a taxa de remuneração (long-term target payout ratio -, que denotaremos simplesmente por meta de remuneração);

$\mathrm{D}_{\mathrm{t}+\mathrm{l}}$ e $\mathrm{D}_{\mathrm{t}}=$ dividendos para o ano $\mathrm{t}+\mathrm{l}$ e $\mathrm{t}$, respectivamente; $\mathrm{e}$

SOA $=$ velocidade de ajustamento.

Para simplificar a notação, nesta e nas demais equações do trabalho omitiremos o termo subscrito das firmas nas variáveis e no resíduo e o termo subscrito dos anos nos coeficientes da regressão.

Nosso principal objetivo é examinar como o TP da equação (4.1) varia entre as firmas como função das oportunidades de investimento, lucratividade, alavancagem e volatilidade. Para isso, primeiro regride-se a razão dos dividendos sobre o ativo total $\left(\mathrm{D}_{\mathrm{t}+\mathrm{l}} / \mathrm{A}_{\mathrm{t}+\mathrm{l}}\right)$ na razão do lucro líquido sobre $\mathrm{o}$ ativo total $\left(\mathrm{Y}_{\mathrm{t}+1} / \mathrm{A}_{\mathrm{t}+1}\right)$, sem os termos de interação, conforme equação: 


$$
D_{t+1} / A_{t+1}=a_{0}+a_{1}^{*} Y_{t+1} / A_{t+1}+u_{t+1}
$$

O resultado pode ser visto na Tabela 4 , que reporta uma meta de remuneração (TP) de $11 \%$. O sinal positivo e significativo do coeficiente de $\mathrm{Y}_{\mathrm{t}+\mathrm{l}} / \mathrm{A}$ ${ }_{t+1}$ é o esperado pelo modelo de Lintner, que supõe os dividendos como uma parcela do lucro líquido.

Embora o $\mathrm{R}^{2}$ médio igual a 0,25 coincida com o valor de Fama e French (2002), tem-se uma meta de remuneração muito inferior aos $46 \%$ estimados por esses autores para as empresas norte-americanas. Esta diferença indica uma menor distribuição dos lucros das empresas brasileiras em forma de dividendos.

TABELA 4 - ESTIMATIVAS DA EQUAÇÃO (4.2) DE DETERMINAÇÃO DOS DIVIDENDOS

\begin{tabular}{lcccc}
\hline & Int & $\mathrm{Y}_{\mathrm{t}+1} / \mathrm{A}_{\mathrm{t}+1}$ & $\mathrm{TP}$ & $\mathrm{R}^{2}$ \\
\hline Média & 0,01 & 0,11 & 0,11 & 0,25 \\
Estatística t & $(14,15)$ & $(3,78)$ & $(3,78)$ & $(4,38)$ \\
\hline
\end{tabular}

A variável dependente é $\mathrm{D}_{t+1} / \mathrm{A}_{\mathrm{t}+1}$, ou seja, dividendos para o ano fiscal $t+1$ dividido pelo ativo total valor contábil em $t+1$. A regressão foi rodada para cada ano $t+l$ de 1995-2000 (6 anos). A tabela reporta a média (temporal) do coeficiente de inclinação $a_{1}$ e do intercepto $\mathrm{a}_{0}$, representado pelas iniciais Int, descritos na eq. (4.2). A Estatística t é a média dividida pelo erro padrão [o desvio padrão temporal do coeficiente dividido por $6^{1 / 2}$ ]. A variável $\mathrm{Y}_{\mathrm{t}+1}$ é lucro líquido para o ano $\mathrm{t}+\mathrm{l}$. $\mathrm{R}^{2}$ é a média temporal dos $\mathrm{R}^{2}$ seccionais ajustados pelos graus de liberdade. E TP é a média temporal dos coeficientes estimados de $\mathrm{a}_{1}$, calculado no apêndice B. 
No Gráfico 2 podemos observar a dinâmica temporal do coeficiente de inclinação, $a_{1}$ da equação $(4.2) .{ }^{4}$ Percebe-se que a meta de dividendos como proporção do lucro vem crescendo ao longo do tempo, sem, contudo, ultrapassar 20\%. Embora este valor continue inferior ao americano, não deixa de ser interessante notar que os dividendos parecem estar respondendo às mudanças recentes na legislação (descritas na nota $n^{\circ} 1$ ), que tornaram o pagamento de dividendos mais vantajoso. Quanto à evolução temporal do intecepto, no Gráfico 3, não se observa uma tendência clara.

\section{GRÁFICO 2 - EVOLUÇÃO DO COEFICIENTE DE INCLINAÇÃO $a_{1}$ DA EQUAÇÃO(4.2) AO LONGO DOS ANOS DE $1995 \mathrm{~A}$ 2000}

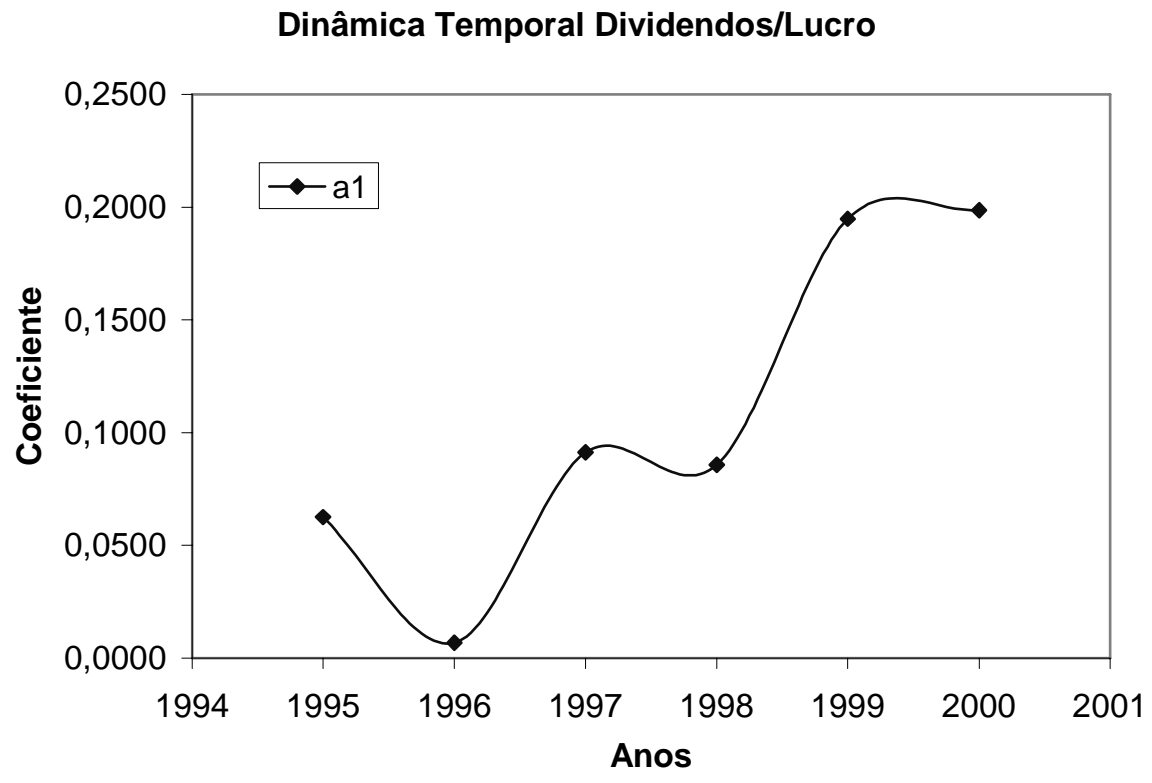

O gráfico acima reporta a dinâmica temporal do coeficiente de inclinação $a_{1}$ da equação (4.2) ao longo dos anos de 1995 a 2000.

4 A idéia desta análise nos foi sugerida pelo parecerista. 
GRÁFICO 3 - EVOLUÇÃO DO INTERCEPTO $a_{0}$ DA EQUAÇÃO (4.2)

AO LONGO DOS ANOS DE 1995 A 2000

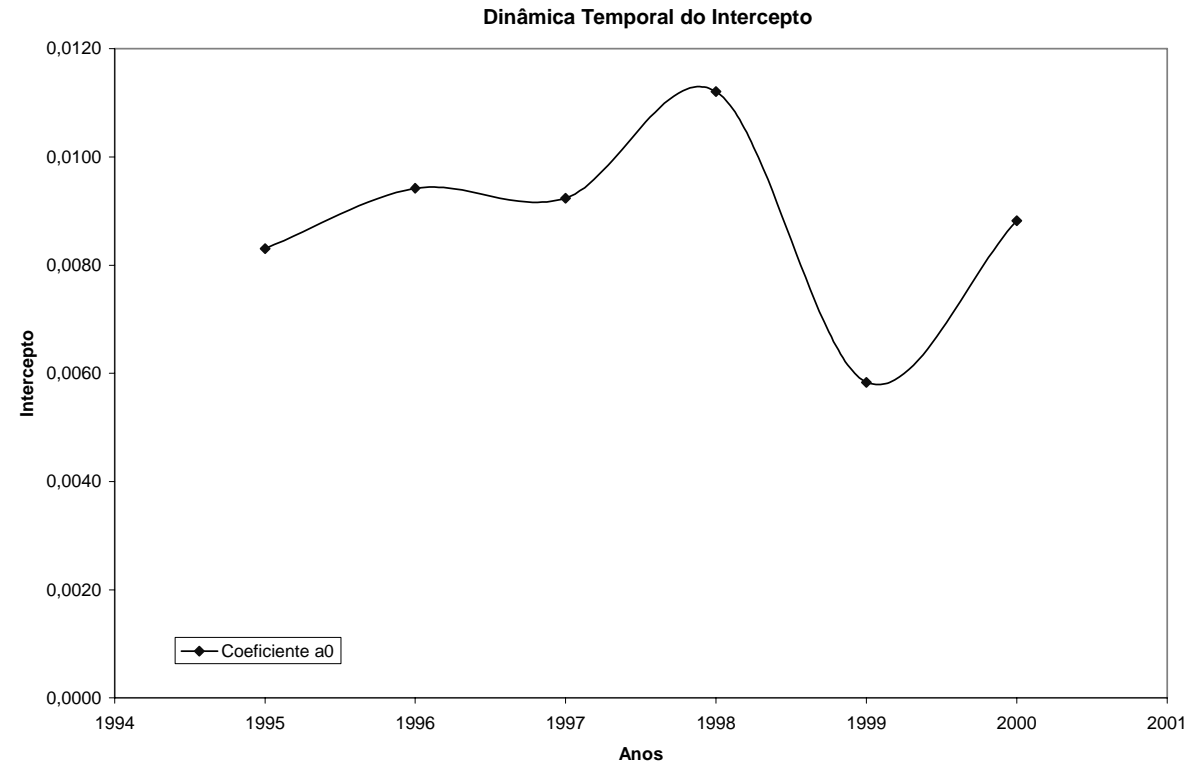

O gráfico acima reporta a dinâmica temporal do intercepto $a_{0}$ da equação (4.2) ao longo dos anos de 1995 a 2000.

A Tabela 5 apresenta a regressão (4.3) descrita abaixo, com os termos de interação:

$\mathrm{D}_{\mathrm{t}+\mathrm{l}} / \mathrm{A}_{\mathrm{t}+\mathrm{l}}=\mathrm{a}_{\mathrm{o}}+\left(\mathrm{a}_{1}+\mathrm{a}_{1 \mathrm{~V}} \mathrm{~V}_{\mathrm{t}} / \mathrm{A}_{\mathrm{t}}+\mathrm{a}_{1 \mathrm{~L}} \mathrm{E}_{\mathrm{t}} / \mathrm{A}_{\mathrm{t}}+\mathrm{a}_{1 S} \ln \left(\mathrm{A}_{\mathrm{t}}\right)+\right.$

$\left.+a_{1 D} T_{t+1}+a_{1 A} d A_{t} / A_{t}\right)^{*} Y_{t+1} / A_{t+1}+u_{t+1}$

Ou seja, nesta segunda etapa, pela introdução de termos de interação, permite-se que a meta de remuneração (TP) varie entre as empresas em função das oportunidades de investimento, lucratividade, volatilidade, alavancagem e investimento.

O painel A da Tabela 5 apresenta as estimativas da equação (4.3) na sua forma reduzida, ou seja, sem o termo de alavancagem $\left(\mathrm{TL}_{\mathrm{t}+1}\right)$, a fim de se evitar um problema de endogeneidade entre as variáveis de alavancagem e dividendos. Os valores estimados na forma reduzida servirão como proxy para a variável que mede dividendos, $\mathrm{TP}_{\mathrm{t}+\mathrm{l}}$, na equação $(6.1)$. Neste pri- 
meiro painel, apenas a variável de lucratividade, $\mathrm{E}_{\mathrm{t}} / \mathrm{A}_{\mathrm{t}}$, é significativa, apresentando sinal positivo. Embora as teorias de trade-off e pecking order compartilhem esta previsão de relação positiva entre lucratividade e dividendos, as forças que influenciam tais expectativas são diferentes. No modelo de trade-off, dado um nível de endividamento preestabelecido, as empresas com maior lucratividade distribuirão mais dividendos para diminuir os custos de agência do excesso de caixa livre. Já no modelo de pecking order, empresas menos lucrativas distribuirão menos dividendos porque têm um custo maior de disponibilizar recursos internos escassos.

TABELA 5 - ESTIMATIVAS DA EQUAÇÃO (4.3) DE DETERMINAÇÃO DOS DIVIDENDOS

\begin{tabular}{|c|c|c|c|c|c|c|c|c|c|}
\hline & \multirow[b]{2}{*}{ Int } & \multirow[b]{2}{*}{$Y_{t+1} / A_{t+1}$} & \multicolumn{5}{|c|}{$Y_{t+1} / A_{t+1}{ }^{*}$} & \multirow[b]{2}{*}{ TP } & \multirow[b]{2}{*}{$\mathrm{R}^{2}$} \\
\hline & & & $V_{t} / A_{t}$ & $E_{t} / A_{t}$ & $\operatorname{LN}\left(A_{t}\right)$ & $\mathrm{TL}_{\mathrm{t}+1}$ & $d A_{t} / A_{t}$ & & \\
\hline \multicolumn{10}{|l|}{ Painel A } \\
\hline Média & 0,006 & $-0,069$ & 0,019 & 0,460 & 0,013 & & 0,002 & 0,15 & 0,41 \\
\hline Estatística t & $(6,52)$ & $(-0,40)$ & $(0,49)$ & $(3,79)$ & $(1,03)$ & & $(0,06)$ & $(2,07)$ & $(7,06)$ \\
\hline \multicolumn{10}{|l|}{ Painel B } \\
\hline Média & 0,006 & 0,376 & 0,198 & 0,376 & $-0,005$ & $-0,584$ & $-0,018$ & 0,14 & 0,47 \\
\hline Estatística t & $(6,76)$ & $(0,79)$ & $(1,36)$ & $(3,37)$ & $(-0,22)$ & $(-1,30)$ & $(-0,39)$ & $(2,06)$ & $(8,08)$ \\
\hline \multicolumn{10}{|l|}{ Painel C } \\
\hline Média & 0,006 & 0,474 & 0,292 & & $-0,0003$ & $-1,018$ & $-0,019$ & 0,14 & 0,43 \\
\hline Estatística t & $(9,70)$ & $(1,19)$ & $(1,93)$ & & $(-0,01)$ & $(-2,20)$ & $(-0,42)$ & $(2,16)$ & $(8,69)$ \\
\hline
\end{tabular}

A variável dependente é $\mathrm{D}_{\mathrm{t}+\mathrm{l}} / \mathrm{A}_{\mathrm{t}+\mathrm{l}}$, ou seja, dividendos para o ano fiscal $\mathrm{t}+\mathrm{l}$ dividido pelo ativo total valor contábil em $t+1$. A regressão foi rodada para cada ano $t+1$ de 1995-2000 (6 anos). A tabela reporta a média (temporal) dos coeficientes de inclinação descritos na eq. (4.3). O intercepto da regressão está representado pelas iniciais Int. A Estatística t é a média dividida pelo erro padrão [o desvio padrão temporal do coeficiente dividido por $6^{1 / 2}{ }_{\text {] }}$. A variável $\mathrm{Y}_{\mathrm{t}+\mathrm{l}}$ é lucro líquido para o ano $\mathrm{t}+\mathrm{l}$. $\mathrm{V}_{\mathrm{t}}$ é o valor de mercado do Ativo Total representado pela soma do valor de mercado das açóes e passivo total para o ano t, $\mathrm{E}_{\mathrm{t}}$ é o lucro antes do imposto de renda para o ano $t, \mathrm{TL}_{\mathrm{t}+1}$ é a meta de alavancagem para $\mathrm{t}+\mathrm{l} . \mathrm{R}^{2}$ é a média temporal dos $\mathrm{R}^{2}$ seccionais ajustados pelos graus de liberdade. $\mathrm{E}$ TP é a média temporal de $a_{1}+a_{1 V} \operatorname{Mn}\left(V_{t} / A_{t}\right)+a_{1 L} M n\left(E_{t} / A_{t}\right)+a_{1 S} \operatorname{Mn}\left(\ln \left(A_{t}\right)\right)+a_{1 D} \operatorname{Mn}(T L t+1)+a_{1 A}$ $\operatorname{Mn}\left(\mathrm{d} \mathrm{A}_{\mathrm{t}} / \mathrm{A}_{\mathrm{t}}\right)$, onde $\mathrm{Mn}(\mathrm{)})$ são as médias seccionais das variáveis por ano e os a's são os coeficientes da equação $(4.3)$. 
O painel B reporta a regressão da equação (4.3) em sua forma estrutural. A variável de alavancagem $\left(\mathrm{TL}_{\mathrm{t}+1}\right)$ utilizada é a sua previsão segundo os coeficientes estimados na forma reduzida da equação (6.1), apresentados no painel A da Tabela 8. Novamente, apenas a variável de lucratividade, $\mathrm{E}_{\mathrm{t}} / \mathrm{A}_{\mathrm{t}}$, é significativa.

Porque existe suspeita de colinearidade entre as demais variáveis e a lucratividade, o painel $\mathrm{C}$ da Tabela 5 reestima a equação (4.3) omitindo essa última. Agora, a alavancagem torna-se significativamente negativa, o que reforça a previsão das teorias de trade-off e pecking order de que firmas mais alavancadas distribuem menos dividendos.

Também podemos perceber que, ao excluírmos $\mathrm{E}_{\mathrm{t}} / \mathrm{A}_{\mathrm{t}}$, a variável $\mathrm{V}_{\mathrm{t}} / \mathrm{A}_{\mathrm{t}}$ torna-se mais positiva e significativa, indicando como mais provável que a inclinação de $V_{t} / A_{t}$ seja devida à informação sobre a lucratividade presente $e$ não sobre oportunidades de crescimento.

As estimativas de TP da Tabela $4(0,15 ; 0,14$ e 0,14$)$ foram mais uma vez menores que as de Fama e French (2002): $(0,42 ; 0,41$ e 0,41). Isto confirma que as empresas brasileiras têm uma meta de remuneração de aproximadamente $15 \%$ do lucro líquido, enquanto nos Estados Unidos distribui-se em torno de $41 \%$ do lucro líquido na forma de dividendos. A menor meta de remuneração das empresas brasileiras é um resultado muito curioso, dada a legislação brasileira favorável (descrita na seção 1.1.1).

Uma explicação para este contra-senso pode ser o maior custo de oportunidade dos recursos próprios, elevados pelo alto custo do capital de terceiros no Brasil.

Diferenças de legislação e de custo de oportunidade do capital próprio a parte, dois modelos de custo de agência disputam a explicação da decisão de dividendos. De acordo com o primeiro, os dividendos respondem à pressão dos minoritários; já pelo segundo, os controladores decidem pelo pagamento, interessados em sinalizar boas características. Sendo assim, a primeira teoria prevê uma relação positiva entre dividendos e direitos dos minoritários, enquanto que a última prevê o oposto. Neste contexto, a comparação entre 
empresas brasileiras e americanas estaria confirmando que os dividendos são pagos por pressão dos minoritários, dada a evidência que estes últimos são mais protegidos nos EUA que no Brasil, como em La Porta et al. (2000).

\section{AJUSTAMENTO DOS DIVIDENDOS}

O principal foco desta seção é testarmos se as empresas brasileiras ajustam suas metas de dividendos quando variações de curto prazo ocorrem nos investimentos. Para esta análise reapresentamos a equação de ajustamento parcial proposta por Lintner:

$$
\mathrm{D}_{\mathrm{t}+1}-\mathrm{D}_{\mathrm{t}}=\operatorname{SOA}\left(\mathrm{TD}_{\mathrm{t}+1}-\mathrm{D}_{\mathrm{t}}\right)+\mathrm{u}_{\mathrm{t}+\mathrm{l}}
$$

A idéia por traz desta equação é que as firmas, por terem um alto custo de ajustamento, não ajustam instantaneamente, mas fazem um ajuste gradual dos dividendos.

Substituindo a equação (4.1) na equação (5.1), obtemos a eq. (5.2):

$$
D_{t+1}-D_{t}=a_{1} Y_{t+1}+a_{2} D_{t}+u_{t+1}
$$

onde:

SOA é definido como a velocidade do ajustamento;

$\mathrm{a}_{2}=-\mathrm{SOA} ; \mathrm{e}$

$\mathrm{a}_{1}=$ TP $\times$ SOA.

Dividindo (5.2) pelo ativo total e adicionando a variável $\mathrm{dA}_{\mathrm{t}+1} / \mathrm{A}_{\mathrm{t}+1}$ para medirmos a resposta de curto prazo dos dividendos ao investimento, obtemos:

$\left(D_{t+1}-D_{t}\right) / A_{t+1}=a_{0}+a_{1} Y_{t+1} / A_{t+1}+a_{2} D_{t} / A_{t+1}+$

$+\mathrm{a}_{3} \mathrm{~d} \mathrm{~A}_{\mathrm{t}+\mathrm{l}} / \mathrm{A}_{\mathrm{t}+1}+\mathrm{u}_{\mathrm{t}+1}$ 
TABELA 6 - ESTIMATIVAS DA EQUAÇÃO (5.3) DE AJUSTAMENTO DOS DIVIDENDOS

\begin{tabular}{lccccccc}
\hline & Int & $Y_{t+1} / A_{t+1}$ & $D_{t} / A_{t+1}$ & $d_{A_{t+1} / A_{t+1}}$ & $S O A$ & $T P$ & $R^{2}$ \\
\hline \multirow{2}{*}{ Média } & 0,01 & 0,10 & $-0,64$ & $-0,01$ & 0,64 & 0,15 & 0,54 \\
Estatística t & $(9,29)$ & $(4,32)$ & $(-6,89)$ & $(-1,16)$ & & & $(5,14)$ \\
\hline
\end{tabular}

A variável dependente é $\left(D_{t+1}-D_{t}\right) / A_{t+1}$. A regressão foi rodada para cada ano $t+l$ de 1995-2000 (6 anos). A tabela reporta a média (temporal) dos coeficientes de inclinação descritos na eq. (5.3). O intercepto da regressão está representado pelas iniciais Int. A Estatística t é a média dividida pelo erro padrão [o desvio padrão temporal do coeficiente dividido por $6^{1 / 2}{ }_{1}$. A variável $\mathrm{Y}_{\mathrm{t}+1}$ é lucro líquido para o ano $\mathrm{t}+1$. $\mathrm{D}_{\mathrm{t}}$ é $\mathrm{o}$ valor dos dividendos para o ano $t, \mathrm{dA}_{\mathrm{t}+1}$ é a diferença entre os ativos totais do ano $\mathrm{t}+\mathrm{l}$ e $\mathrm{t}$. A velocidade de ajustamento, SOA, é igual a menos o coeficiente de inclinação em $\mathrm{D}_{t} / \mathrm{A}_{\mathrm{t}+1}$. E TP é a inclinação média de $\mathrm{Y}_{\mathrm{t}+1} / \mathrm{A}_{\mathrm{t}+1}$ dividido por SOA (ver apêndice $\mathrm{B}$ ). $\mathrm{R}^{2}$ é a média temporal dos $\mathrm{R}^{2}$ seccionais ajustados pelos graus de liberdade.

A Tabela 6 apresenta uma estimativa de 0,64 para a velocidade de ajustamento dos dividendos, SOA da equação (5.3), que é bem mais alta que os 0,33 obtidos por Fama e French (2002) para os EUA. Portanto, podemos dizer que as empresas brasileiras possuem uma alta velocidade de ajustamento aos dividendos. Se isso ocorre devido a menores custos de ajustamento, ou simples restrição de liquidez, foge ao escopo da equação (5.3).

Observa-se, ainda na Tabela 6 , um coeficiente não-significativo para $\mathrm{dA}_{\mathrm{t}+1} /$ $A_{t+1}$, o que indica que os investimentos não são absorvidos por variações de curto prazo nos dividendos.

Uma análise mais detalhada é possível pela inclusão de termos de interação na equação (5.3):

$$
\begin{aligned}
& \left(D_{t+1}-D_{t}\right) / A_{t+1}=a_{0}+\left(a_{1}+a_{1 V} V_{t} / A_{t}+a_{1 L} E_{t} / A_{t}+\right. \\
& \left.+a_{1 S} \ln \left(A_{t}\right)+a_{1 D} T L_{t+1}+a_{1 A} d A_{t} / A_{t}\right) Y_{t+1} / A_{t+1}+ \\
& +\left(a_{2}+a_{2 V} V_{t} / A_{t}+a_{2 L} E_{t} / A_{t}+a_{2 S} \ln \left(A_{t}\right)+a_{2 D} T L_{t+1}+\right. \\
& \left.+a_{2 A} d A_{t} / A_{t}\right) D_{t} / A_{t+1}+a_{3} d A_{t+1} / A_{t+1}+u_{t+1}
\end{aligned}
$$


Isto permitirá uma variação dos TP's e SOA's entre as firmas em função das oportunidades de investimento, lucratividade, volatilidade, alavancagem e investimento líquido.

TABELA 7 - ESTIMATIVAS DA EQUAÇÃO (5.4) DE AJUSTAMENTO DOS DIVIDENDOS

\begin{tabular}{lccccccc}
\hline & Int & $\mathrm{Y}_{\mathrm{t}+1} / \mathrm{A}_{\mathrm{t}+1}$ & $\mathrm{D}_{\mathrm{t}} / \mathrm{A}_{\mathrm{t}+1}$ & $\mathrm{~d} \mathrm{~A}_{\mathrm{t}+1} / \mathrm{A}_{\mathrm{t}+1}$ & $\mathrm{SOA}$ & $\mathrm{TP}$ & $\mathrm{R}^{2}$ \\
\hline Média & 0,004 & 0,115 & $-0,703$ & $-0,004$ & 0,703 & 0,163 & 0,750 \\
Estatística t & $(4,45)$ & $(5,28)$ & $(-10,83)$ & $(-0,77)$ & & & $(25,75)$ \\
\hline
\end{tabular}

A variável dependente é $\left(\mathrm{D}_{t+1}-\mathrm{D}_{\mathrm{t}}\right) / \mathrm{A}_{\mathrm{t}+1}$. A regressão foi rodada para cada ano $\mathrm{t}+\mathrm{l}$ de 1995-2000 (6 anos). A tabela reporta a média (temporal) dos coeficientes de inclinação descritos na eq. (5.4). O intercepto da regressão está representado pelas iniciais Int. A Estatística t é a média dividida pelo erro padrão [o desvio padrão temporal do coeficiente dividido por $6^{1 / 2}{ }_{1}$. A variável $\mathrm{Y}_{\mathrm{t}+1}$ é lucro líquido para o ano $\mathrm{t}+\mathrm{l}$. $\mathrm{D}_{\mathrm{t}}$ é $\mathrm{o}$ valor dos dividendos para o ano $t, \mathrm{~d} \mathrm{~A}_{\mathrm{t}+1}$ é a diferença entre os ativos totais do ano $t+l$ e t. A velocidade de ajustamento, SOA, é igual a menos o coeficiente de inclinação em $\mathrm{D}_{t} / \mathrm{A}_{t+1}$. E TP é a inclinação média de $Y_{t+1} / A_{t+1}$ dividido por SOA. $O$ coeficiente de inclinação em $Y_{t+1} / A_{t+1}$ é a média temporal de $\mathrm{a}_{1}+\mathrm{a}_{1 \mathrm{~V}} \operatorname{Mn}\left(\mathrm{V}_{\mathrm{t}} / \mathrm{A}_{\mathrm{t}}\right)+\mathrm{a}_{1 \mathrm{~L}} \mathrm{Mn}\left(\mathrm{E}_{\mathrm{t}} / \mathrm{A}_{\mathrm{t}}\right)+\mathrm{a}_{1 S} \operatorname{Mn}\left(\ln \left(\mathrm{A}_{\mathrm{t}}\right)\right)+\mathrm{a}_{1 \mathrm{D}} \mathrm{Mn}$ $\left(\mathrm{L}_{\mathrm{t}+1}\right)+\mathrm{a}_{1 \mathrm{~A}} \operatorname{Mn}\left(\mathrm{d} \mathrm{A}_{\mathrm{t}} / \mathrm{A}_{\mathrm{t}}\right)$, onde $\operatorname{Mn}()$ são as médias seccionais das variáveis por ano e os $\mathrm{a}_{1}$ 's são os coeficientes da eq. (5.4). A inclinação em $\mathrm{D}_{\mathrm{t}} / \mathrm{A}_{\mathrm{t}+1}$ é a média temporal de $\mathrm{a}_{2}+$ $a_{2 V} \operatorname{Mn}\left(V_{t} / A_{t}\right)+a_{2 L} M n\left(E_{t} / A_{t}\right)+a_{2 S} M n\left(\ln \left(A_{t}\right)\right)+a_{2 D} M n\left(L_{t+1}\right)+a_{2 A} M n\left(d A_{t} / A_{t}\right)$, onde $\operatorname{Mn}\left(\right.$ ) são as média seccional das variáveis por ano e os $\mathrm{a}_{2}$ 's são os coeficientes da equação (5.4). $\mathrm{R}^{2}$ é a média temporal dos $\mathrm{R}^{2}$ seccionais ajustados pelos graus de liberdade.

$\mathrm{Na}$ Tabela 7, as estimativas de 0,16 e 0,7 , respectivamente para os coeficientes de TP e SOA, são bastante parecidas com as obtidas na Tabela $6(0,15$ e $0,64)$, porém com $\mathrm{R}^{2}$ médio maior. Como na equação (5.3), os dividendos não respondem aos investimentos $\left(\mathrm{dA}_{\mathrm{t}+1} / \mathrm{A}_{\mathrm{t}+1}\right)$.

Ou seja, por um lado as Tabelas 6 e 7 confirmam o aspecto da pecking order, que prevê pouca resposta dos dividendos às variações de curto prazo dos investimentos devido ao maior custo de variar dividendos relativamente à dívida. Por outro lado, põem em dúvida a previsão da pecking order de baixa velocidade de ajustamento. Em síntese, no Brasil, embora os dividendos se apresentem insensíveis ao investimento, parecem depender bastante dos lucros correntes. 


\section{DETERMINANTES DE DÍVIDA}

Nesta seção observam-se os fatores determinantes do endividamento das empresas brasileiras e relacionam-se os resultados com o previsto pelas teorias de trade-off e pecking order.

Primeiro regredimos a variável de endividamento total em valor contábil nas variáveis de oportunidades de investimento, lucratividade, volatilidade, variação do investimento e dividendos, conforme equação (6.1) descrita abaixo:

$\mathrm{L}_{\mathrm{t}+\mathrm{l}} / \mathrm{A}_{\mathrm{t}+\mathrm{l}}=\mathrm{b}_{0}+\mathrm{b}_{1} \mathrm{~V}_{\mathrm{t}} / \mathrm{A}_{\mathrm{t}}+\mathrm{b}_{2} \mathrm{ET}_{\mathrm{t}} / \mathrm{A}_{\mathrm{t}}+\mathrm{b}_{3} \ln \left(\mathrm{A}_{\mathrm{t}}\right)+$

$+b_{4} d A_{t} / A_{t}+b_{5} T P_{t+1}+u_{t+1}$

onde $\mathrm{ET}_{\mathrm{t}} / \mathrm{A}_{\mathrm{t}}$ é o lucro operacional próprio, no lugar do lucro antes do imposto de renda $\left(\mathrm{E}_{\mathrm{t}} / \mathrm{A}_{\mathrm{t}}\right)$ utilizado anteriormente para determinantes de dividendos. Esta substituição se justifica por estarmos interessados em capturar os efeitos dos impostos no endividamento total das empresas, previsto pelo modelo de trade-off.

A variável de dividendos $\left(\mathrm{TP}_{\mathrm{t}+1}\right)$ utilizada é a sua previsão segundo os coeficientes estimados na forma reduzida da equação (4.3), apresentados no painel A da Tabela 5. Assim, pretendemos resolver o problema de endogeneidade existente entre as variáveis de endividamento e dividendos.

O painel A da Tabela 8 reporta as estimativas da equação (6.1) em sua forma reduzida. Pode-se dizer que as variáveis de oportunidades de investimento, lucratividade e tamanho apresentaram-se como fatores determinantes da política de endividamento total das empresas brasileiras. O sinal negativo da lucratividade indica que firmas mais lucrativas são menos endividadas. Isso confirma a previsão de pecking order, na qual as empresas não recorrem ao financiamento externo antes de esgotarem seus recursos próprios. Por outro lado, esse resultado rejeita a teoria da trade-off, na qual as firmas se endividam mais para minimizar a possibilidade de gastos não-produtivos dos recursos livres. Rajan e Zingales (1995), entre outros, também encontraram a mesma relação negativa. 
TABELA 8 - ESTIMATIVAS DA EQUAÇÃO (6.1) DE DETERMINAÇÃO DO ENDIVIDAMENTO

\begin{tabular}{|c|c|c|c|c|c|c|c|}
\hline & Int. & $V_{t} / A_{t}$ & $E T_{t} / A_{t}$ & $\operatorname{LN}\left(A_{t}\right)$ & $d A_{t} / A_{t}$ & $\mathrm{TP}_{\mathrm{t}+1}$ & $\mathrm{R}^{2}$ \\
\hline \multicolumn{8}{|l|}{ Painel A } \\
\hline Média & 0,783 & 0,325 & $-0,746$ & $-0,030$ & $-0,021$ & & 0,273 \\
\hline Estatística t & $(8,97)$ & $(4,14)$ & $(-3,43)$ & $(-5,57)$ & $(-0,49)$ & & $(5,91)$ \\
\hline \multicolumn{8}{|l|}{ Painel B } \\
\hline Média & 0,585 & 0,303 & 0,083 & 0,000 & $-0,005$ & $-1,902$ & 0,360 \\
\hline Estatística t & $(9,16)$ & $(4,06)$ & $(0,46)$ & $(0,09)$ & $(-0,10)$ & $(-6,56)$ & $(7,22)$ \\
\hline \multicolumn{8}{|l|}{ Painel C } \\
\hline Média & 0,586 & 0,306 & & 0,000 & $-0,002$ & $-1,831$ & 0,353 \\
\hline Estatística t & $(10,08)$ & $(4,02)$ & & $(-0,08)$ & $(-0,06)$ & $(-6,13)$ & $(7,13)$ \\
\hline
\end{tabular}

A variável dependente é $\mathrm{L}_{\mathrm{t}+1} / \mathrm{A}_{\mathrm{t}+1} . \mathrm{L}_{\mathrm{t}+1}=\left(\mathrm{ELP}_{\mathrm{t}+1}+\mathrm{PC}_{\mathrm{t}+1}\right)$ é o valor contábil do passivo total, ou seja, é a soma do Exigível de Longo Prazo e Passivo Circulante no ano $t+1$. A regressão foi rodada para cada ano $t+1$ de 1995-2000 (6 anos). A tabela reporta a média (temporal) dos coeficientes de inclinação descritos na eq. (6.1). O intercepto da regressão está representado pelas iniciais Int. A Estatística t é a média dividida pelo erro padrão [o desvio padrão temporal do coeficiente dividido por $6^{1 / 2}{ }_{1} \mathrm{~V}_{\mathrm{t}}$ é o valor de mercado do Ativo total representado pela soma do valor de mercado das ações e passivo total para o ano $t, \mathrm{ET}_{t}$ é o lucro operacional próprio para o ano t. $\mathrm{ETP}_{\mathrm{t}+1} \mathrm{e}^{\mathrm{a}} \mathrm{a}_{1}+\mathrm{a}_{1 \mathrm{~V}}\left(\mathrm{~V}_{\mathrm{t}} / \mathrm{A}_{\mathrm{t}}\right)+\mathrm{a}_{1 \mathrm{~L}}\left(\mathrm{E}_{\mathrm{t}} / \mathrm{A}_{\mathrm{t}}\right)+\mathrm{a}_{1 \mathrm{~S}}$ $\left(\ln \left(A_{t}\right)\right)+a_{1 A}\left(d A_{t} / A_{t}\right)$, onde os as são os coeficientes da equação forma reduzida da equação (4.3). $\mathrm{R}^{2}$ é a média temporal dos $\mathrm{R}^{2}$ seccionais ajustados pelos graus de liberdade.

$\mathrm{O}$ coeficiente positivo e significativo de $\mathrm{V}_{\mathrm{t}} / \mathrm{A}_{\mathrm{t}}$, que mede oportunidades de investimento, também confirma o previsto pela pecking order, que diz que firmas com maiores oportunidades de investimento são mais endividadas. Como a previsão de trade-off é de sinal negativo (ver Tabela 2), podemos afirmar que os dados brasileiros a rejeitam.

O sinal esperado segundo ambas as teorias para a variável de tamanho é o positivo, ou seja, espera-se que as maiores firmas possuam fluxos de caixa menos voláteis, maior facilidade em obter créditos e, por isso, sejam as mais endividadas. Porém, encontramos sinal negativo para o coeficiente de tama- 
nho que serve como proxy para a volatilidade. Este sinal contraditório já apareceu em outros estudos brasileiros como Gomes e Leal (2001) ou Perobelli e Famá (2002).

O painel B reporta a regressão da equação (6.1) em sua forma estrutural, considerando a meta dos dividendos como variável explicativa. A estimativa negativa e significativa do coeficiente desta última confirma ambas as teorias de trade-off e pecking order, as quais prevêem que firmas mais endividadas devem distribuir menos dividendos.

Apesar do coeficiente das oportunidades de investimento não mudar qualitativamente, as variáveis lucratividade e tamanho perdem a significância, indicando que suas aparentes importâncias eram devidas aos seus papéis na explicação da meta de remuneração.

Como existe o problema de colineariedade entre as variáveis meta de remuneração e lucratividade, no painel $\mathrm{C}$ omitimos a variável de lucratividade. As estimativas dos coeficientes remanescentes se mostraram próximas das encontradas no painel $\mathrm{B}$, confirmando que há relação entre o endividamento e a meta de remuneração.

\section{AJUSTAMENTO DA DÍVIDA}

Segundo prevê a teoria de trade-off, o endividamento é um processo que reverte ao nível ótimo de alavancagem da firma. O objetivo desta seção é testar tal particularidade ou se variações de curto prazo em lucros e investimentos são permanentemente absorvidas por dívida, conforme previsto pela teoria da pecking order. Para isso, estima-se a regressão:

$$
\begin{aligned}
& \mathrm{L}_{\mathrm{t}+1} / \mathrm{A}_{\mathrm{t}+1}-\mathrm{L}_{\mathrm{t}} / \mathrm{A}_{\mathrm{t}}=\mathrm{c}_{\mathrm{o}}+\mathrm{c}_{1} \mathrm{TL}_{\mathrm{t}+1}+\mathrm{c}_{2} \mathrm{~L}_{\mathrm{t}} / \mathrm{A}_{\mathrm{t}}+ \\
& +\mathrm{c}_{3} \mathrm{dE}_{\mathrm{t}+1} / \mathrm{A}_{\mathrm{t}+1}+\mathrm{c}_{4} \mathrm{~d} \mathrm{~A}_{\mathrm{t}+\mathrm{l}} / \mathrm{A}_{\mathrm{t}+\mathrm{l}}+\mathrm{u}_{\mathrm{t}+\mathrm{l}}
\end{aligned}
$$

cujos resultados estão reportados na Tabela 9. 
TABELA 9 - ESTIMATIVA DA EQUAÇÃO (7.1) DE AJUSTAMENTO $D A D I V I D A$

\begin{tabular}{lcccccc}
\hline & Int. & $\mathrm{TL}_{\mathrm{t}+1}$ & $\mathrm{~L}_{\mathrm{t}} / \mathrm{A}_{\mathrm{t}}$ & $\mathrm{dE}_{\mathrm{t}+1} / \mathrm{A}_{\mathrm{t}+1}$ & $\mathrm{dA}_{\mathrm{t}+1} / \mathrm{A}_{\mathrm{t}+1}$ & $\mathrm{R}^{2}$ \\
\cline { 3 - 6 } Média & 0.047 & 0.184 & -0.218 & -0.285 & 0.012 & 0.252 \\
Estatística t & $(1.11)$ & $(2.00)$ & $(-4.17)$ & $(-2.93)$ & $(0.27)$ & $(6.37)$
\end{tabular}

A variável dependente é $\mathrm{L}_{\mathrm{t}+1} / \mathrm{A}_{\mathrm{t}+1} \cdot \mathrm{L}_{\mathrm{t}} / \mathrm{A}_{\mathrm{t}} \cdot \mathrm{L}_{\mathrm{t}+1}=\left(\mathrm{ELP}_{\mathrm{t}+1}+\mathrm{PC}_{\mathrm{t}+1}\right)$ é o valor contábil do passivo total, ou seja, é a soma do Exigível de Longo Prazo e Passivo Circulante no ano $\mathrm{t}+\mathrm{l}$. A regressão foi rodada para cada ano $\mathrm{t}+\mathrm{l}$ de 1995-2000 (6 anos). A tabela reporta a média (temporal) dos coeficientes de inclinação descritos na eq. (7.1). O intercepto da regressão está representado pelas iniciais Int. A Estatística t é a média dividida pelo erro padrão [o desvio padrão temporal do coeficiente dividido por $6^{1 / 2}{ }_{1} \mathrm{TL}_{\mathrm{t}+1}$ é o valor estimado da regressão de $\mathrm{L}_{\mathrm{t}+1} / \mathrm{A}_{\mathrm{t}+1} \mathrm{em} \mathrm{V} \mathrm{V}_{\mathrm{t}} / \mathrm{A}_{\mathrm{t}}, \mathrm{ET}_{\mathrm{t}} / \mathrm{A}_{\mathrm{t}} \ln \left(\mathrm{A}_{\mathrm{t}}\right), \mathrm{d} \mathrm{A} \mathrm{A}_{\mathrm{t}} / \mathrm{A}_{\mathrm{t}} \mathrm{eTP}_{\mathrm{t}+1} . \mathrm{ETP}_{\mathrm{t}+1}$ é $\mathrm{a}_{1}+$ $a_{1 V}\left(V_{t} / A_{t}\right)+a_{1 L}\left(E_{t} / A_{t}\right)+a_{1 S}\left(\ln \left(A_{t}\right)\right)+a_{1 A}\left(d A_{t} / A_{t}\right)$, onde os a's são os coeficientes da equação forma reduzida da equação (4.3). $\mathrm{R}^{2}$ é a média temporal dos $\mathrm{R}^{2}$ seccionais ajustados pelos graus de liberdade.

Embora as estimativas dos coeficientes de $\mathrm{TL}_{t+1}$ e $\mathrm{L}_{t} / \mathrm{A}_{\mathrm{t}}$ sugiram lenta reversão à meta do endividamento como previsto por trade-off, preferimos a interpretação de Graham e Harvey (2000), segundo os quais as firmas declaram ter metas de endividamento cujo atendimento é de importância secundária. Shyam Sunder e Myers (1999) apresentam explicação semelhante, apontando que a autocorrelação dos fluxos de caixa líquidos pode gerar lenta reversão à meta sob a regra de pecking order. Como os dividendos são estáveis, o endividamento das empresas cresce nos anos com déficit e decresce quando ocorre superávit.

Ainda em acordo com a pecking order, o coeficiente estimado de $\mathrm{dE}_{\mathrm{t}+1} / \mathrm{A}_{\mathrm{t}+\mathrm{l}}$ confirma que as variações de curto prazo em lucros são realmente absorvidas por dívida.

Porém, não podemos ter a mesma interpretação para o coeficiente da sensibilidade aos investimentos, pois foi observada uma baixa significância de sua estatística de teste $\mathrm{t}$. 


\section{CONCLUSÕES}

As proposições das irrelevâncias da alavancagem e dos dividendos para o valor da firma num mercado perfeito e sem impostos, por Modigliani e Miller (1958 e 1961), estabelecem as bases das modernas teorias de estrutura de capital e política de remuneração ao definirem uma heurística passível de adaptação a outras condições. Por exemplo, pela incorporação de imperfeições como custos de insolvência e agência, o modelo de trade-off determina o nível ótimo de alavancagem e dividendos pela ponderação dos seus custos e benefícios. Ou, se os custos do financiamento por terceiros extrapolam qualquer benefício, o modelo de pecking order conclui que não há grau de alavancagem ótimo, sendo dívida e dividendos definidos pela disponibilidade de caixa.

Neste trabalho, no que diz respeito a dividendos, confirmamos a previsão comum de trade-off e pecking order de que a lucratividade é o fator de maior importância para o pagamento de dividendos. As firmas mais lucrativas destinam uma maior proporção para a remuneração dos seus acionistas, e a relação negativa entre dividendos e alavancagem confirma que estes são substitutos na alocação dos recursos internos da firma. Os fatores oportunidades de investimento e volatilidade não se mostram significativos para explicar a meta de remuneração das empresas brasileiras.

Quanto às previsões contrárias de trade-off e pecking order para a relação entre dívida e lucratividade ou entre dívida e oportunidades de investimento, o segundo modelo parece prevalecer sobre o primeiro. Encontra-se uma relação negativa entre alavancagem e lucratividade, o que sugere que o endividamento ocorre após o esgotamento dos recursos próprios. E uma relação positiva entre alavancagem e oportunidades de investimento indica que as empresas que mais investem acabam se endividando mais.

Confirmando também a previsão da pecking order, as mudanças de curto prazo na lucratividade são absorvidas por dívida. Segundo esta teoria, o resultado se deve ao fato de os custos de ajustamento dos dividendos serem maiores que os custos de ajustamento da dívida. 
Embora os dados brasileiros sugiram que o endividamento das firmas reverte lentamente para uma meta de longo prazo, como previsto por trade-off, preferimos a interpretação de Graham e Harvey (2000), segundo os quais as firmas declaram ter metas de endividamento cujo atendimento é de importância secundária.

Finalmente, é curioso que a meta de distribuição de dividendos das companhias brasileiras seja inferior à das americanas, apesar das legislações nacionais incentivarem o contrário. Uma especulação, que merecerá estudos futuros, é a do maior custo de oportunidade dos recursos próprios, elevados pelo alto custo do capital de terceiros no Brasil.

\section{REFERÊNCIAS BIBLIOGRÁFICAS}

ALLEN, F; MICHAELY, R. Payout policy. In: CONSTANTINIDES, G.; HARRIS, M.; STULZ, R., Handbook of the economics of finance: corporate finance. North-Holland, 2003.

AUERBACH, A. J. Real determinants of corporate leverage. In: FRIEDMAN, B., Corporate capital structures in the United States. Chicago: University of Chicago Press, 1985.

BRITO, R.; LIMA, M. A escolha da estrutura de capital sob fraca garantia legal: o caso do Brasil. Revista Brasileira de Economia, v. 59, p. a definir, 2005.

COCHRANE, J. Asset pricing. Princeton: Princeton University Press, 2001.

DE ANGELO, H.; MASULIS, R. Optimal capital structure under corporate and personal taxation. Journal of Financial Economics, v. 8, p. 329, 1980.

EASTERBROOK, F. Two agency-cost explanations of dividends. American Economic Review, v. 74, p. 650-659, 1984.

FAMA, E.; FRENCH, K. Disappearing dividends: changing firm characteristics or lower propensity to pay? Journal of Financial Economics, v. 60 , p. 3-43, 2001.

. Testing trade-off and pecking order predictions about dividends and debt. The Review of Financial Studies, v. 15, n. 1, p. 1-33, 2002.

FAMA, E.; MACBETH, J. Risk, return and equilibrium: empirical tests. Journal of Political Economy, v. 81, p. 607-636, 1973. 
FIGUEIREDO, A. C. O conteúdo informativo de dividendos: evidências no Brasil. Anais do $2^{\circ}$ Encontro Brasileiro de Finanças, 2002.

GOMES, G.; LEAL, R. Determinantes da estrutura de capitais das empresas brasileiras com ações negociadas em bolsas de valores. In: LEAL, R.; COSTA JR., N.; LEMGRUBER, E. Finanças corporativas. São Paulo: Atlas, 2001.

GRAHAM, J.; HARVEY, C. The theory and practice of corporate finance: evidence from the field. Journal of Financial Economics, forthcoming, 2000.

HARRIS, M.; RAVIV, A. The theory of capital structure. The Journal of Finance, v. 46, n. 1, p. 297-355, 1991.

JALILVAND, A.; HARRIS, R. S. Corporate behavior in ajusting to capital structure and dividend targets: an econometric study. Joumal of Finance, v. 39, p. 127-145, 1984.

JENSEN, M. Agency costs of free-cash-flow, corporate finance, and takeovers. American Economic Review, v. 76, p. 323-329, 1986.

JENSEN, M.; MECKLING, W. Theory of the firm: managerial behavior, agency costs and ownership structure. Journal of Financial Economics, v. 3 , p. $305-360,1976$.

LA PORTA, R.; LOPEZ-DE-SILANES, F; SHLEIFER, A.; VISHNY, $\mathrm{R}$. Agency problems and dividends around the world. The Journal of Finance, v. 55, n. 1, p. 1-33, 2000.

LINTNER, J. The distribution of incomes of corporations among dividends, retained earnings, and taxes. American Review, v. 46, p. 97$113,1956$.

MILLER, M. Debt and taxes. Journal of Finance, v. 32, p. 261-75, 1977.

MILLER, M.; SCHOLES, M. Dividends and taxes. Journal of Financial Economics, v. 6, p. 333-364, 1978.

MILLER, M.; MODIGLIANI, F. Dividend policy, growth and the valuation of shares. Journal of Business, v. 53, p. 433-443, 1963.

. Corporate income taxes and the cost of capital: a correction. American Economic Review, v. 34, p. 411-33, 1961.

MODIGLIANI, F.; MILLER, M. E. The cost of capital, corporation finance and theory of investment. American Economic Review, v. 48, p. 261-297, 1958.

MYERS, S. The capital structure puzzle. Journal of Finance, v. 39, p. 575592,1984

MYERS, S.; MAJLUF, N. Corporate financing and investment decisions when firms have information that investors do not have. Journal of Financial Economics, v. 13, p. 187-221, 1984. 
PEROBELLI, F; FAMÁ, R. Determinantes da estrutura de capital: aplicação a empresas de capital aberto brasileiras. Revista de Administração da Universidade de São Paulo, v. 37, jul-set. 2001.

PROCIANOY , J.; VERDI, R. O efeito clientela no mercado brasileiro. Anais do $2^{\circ}$ Encontro Brasileiro de Finanças, 2002.

RAJAN, R.; ZINGALES, L. What do we know about capital structure? Some evidence from international data. Journal of Finance, v. 50, p. 1421-1460, 1995.

SAITO, R.; LUCINDA, C. Determinantes do endividamento das empresas brasileiras - volume e composição. 2002. Mimeografado.

SHYAM-SUNDER, L.; MYERS, S. Testing static tradeoff against pecking order models of capital structure. Journal of Financial Economics, v. 51, p. 219-244, 1999.

TITMAN, S.; WESSELS, R. The determinants of capital structure choice. Journal of Finance, v. 43, p. 1-19, 1988.

TOBIN, J. A general equilibrium approach to monetary theory. Journal of Money, Credit and Banking, v. 1, p. 15-29, 1969. 
APÊNDICE A - REPORTA A FREQÜÊNCIA DOS PAGAMENTOS DAS EMPRESAS ENTRE 1995 E 2001 (7 ANOS)

\begin{tabular}{|c|c|c|c|c|c|}
\hline Empresas & \# Pag. Div. & Empresas & \# Pag. Div. & Empresas & \# Pag. Div \\
\hline Acesita & 5 & Cia Hering & 3 & Inds Romi & 7 \\
\hline Adubos Trevo & 2 & Cim Itau & 7 & Inepar Construcoes & 6 \\
\hline Alfa Consorcio & 6 & Coelba & 5 & lochp-Maxion & 3 \\
\hline Alfa Holding & 5 & Coelce & 5 & Ipiranga Dist & 4 \\
\hline Alpargatas & 6 & Cofap & 6 & Ipiranga Pet & 3 \\
\hline Ambev & 7 & Confab & 6 & Ipiranga Ref & 4 \\
\hline Aracruz & 7 & Copesul & 6 & Itautec & 4 \\
\hline Avipal & 7 & Coteminas & 7 & Iven & 6 \\
\hline Bahia Sul & 2 & Dixie Toga & 3 & Klabin & 5 \\
\hline Bardella & 7 & Docas & 7 & Light & 6 \\
\hline Belgo Mineira & 7 & Duratex & 7 & Loj Americanas & 5 \\
\hline Bombril & 7 & EDN & 4 & Magnesita & 7 \\
\hline Brasil Telecom & 5 & Electrolux & 4 & Mangels & 7 \\
\hline Braskem & 7 & Eletrobras & 7 & Marcopolo & 4 \\
\hline Brasmotor & 7 & Embraco & 7 & Metal Leve & 5 \\
\hline Bunge Alimentos & 4 & Embraer & 4 & Millennium & 7 \\
\hline Bunge Brasil & 5 & Enersul & 7 & Mont Aranha & 7 \\
\hline Bunge Fertilizantes & 5 & Eternit & 7 & Multibras & 7 \\
\hline Cacique & 7 & F Cataguazes & 2 & Nitrocarbono & 1 \\
\hline Caemi Metal & 6 & Fertibras & 7 & Oxiteno & 7 \\
\hline Cargill Fertilizant & 7 & Fosfertil & 5 & Pao de Acucar & 7 \\
\hline Celesc & 6 & Gerdau Met & 7 & Paraibuna & 2 \\
\hline Cemig & 7 & Gerdau & 7 & Paul F Luz & 7 \\
\hline Cerj & 3 & Gradiente & 4 & Perdigao & 7 \\
\hline Cesp & 6 & Guararapes & 7 & Petrobras Distrib & 6 \\
\hline
\end{tabular}




\begin{tabular}{lcllll}
\hline Empresas & \# Pag. Div. & Empresas & \# Pag. Div. & Empresas & \# Pag. Div. \\
\hline Petrobras & 7 & Ripasa & 3 & Telesp Operac & 7 \\
Petroflex & 5 & Sadia SA & 7 & Trikem & 6 \\
Petropar & 7 & Santista Textil & 6 & Tupy & 3 \\
Petroquimica Uniao & 7 & Sid Nacional ON & 6 & Unipar & 7 \\
Petroquisa & 7 & Sid Tubarao & 7 & Usiminas & 6 \\
Plascar & 2 & Sifco & 1 & Vale Rio Doce & 7 \\
Polialden & 7 & Souto Vidig & 7 & Varig & 5 \\
Politeno & 7 & Souza Cruz & 5 & Vigor & 6 \\
Pronor & 7 & Sultepa PN & 6 & Votorantim \\
Randon Part & 7 & Supergasbras & 6 & Weg & 7 \\
Ren Hermann & 6 & Suzano & 7 & Wembley & 7 \\
Rhodia-Ster & 2 & Teka PN & 6 & Zivi & 7 \\
\hline & & & & 1 \\
\hline
\end{tabular}


APÊNDICE B - ÁLGEBRA DAS REGRESSÕES DE FAMA E FRENCH (2002)

Tomando:

$$
T D_{t+1}=T P \cdot Y_{t+1}
$$

e:

$$
D_{t+1}-D_{t}=S O A \cdot\left(T D_{t+1}-D_{t}\right)
$$

como dados.

(i) Se:

$$
T P=a_{1}
$$

então, a meta de dividendos em $\mathrm{t}+\mathrm{l}$ será:

$$
T D_{t+1}=a_{1} \cdot Y_{t+1}
$$

não tem intercepto, e substituindo $T D_{t+1} \mathrm{em}(2)$ resulta em:

$$
\begin{aligned}
D_{t+1}-D_{t} & =S O A \cdot\left(a_{1} Y_{t+1}-D_{t}\right) \\
& =S O A \cdot a_{1} Y_{t+1}-S O A \cdot D_{t} \\
& =a_{1} \cdot Y_{t+1}+a_{2} \cdot D_{t}
\end{aligned}
$$

Onde: $a_{1}{ }^{\prime}=S O A \cdot a_{1}, a_{2}=-S O A$, e o teórico intercepto igual a zero.

O que significa:

$$
\begin{aligned}
-\frac{a_{1}{ }^{\prime}}{a_{2}} & =-\frac{S O A \cdot a_{1}}{-S O A}=a_{1} \\
& =T P
\end{aligned}
$$

(ii) Se:

$$
T P=\frac{a_{0}}{Y_{t+1}}+a_{1}
$$


Então, a meta de dividendos para $t+1$ será:

$$
T D_{t+1}=a_{0}+a_{1} \cdot Y_{t+1}
$$

com intercepto, e substituindo $T D_{t+1}$ em (2) temos:

$$
\begin{aligned}
D_{t+1}-D_{t} & =S O A \cdot\left(a_{0}+a_{1} Y_{t+1}-D_{t}\right) \\
& =S O A \cdot a_{0}+S O A \cdot a_{1} Y_{t+1}-S O A \cdot D_{t} \\
& =a_{0}{ }^{\prime}+a_{1}{ }^{\prime} \cdot Y_{t+1}+a_{2} \cdot D_{t}
\end{aligned}
$$

onde: $a_{0}{ }^{\prime}=S O A \cdot a_{0}$ é o intercepto, $a_{1}{ }^{\prime}=S O A \cdot a_{1}$ e $a_{2}=-S O A$.

O que significa:

$$
\begin{aligned}
-\frac{a_{1}{ }^{\prime}}{a_{2}} & =-\frac{S O A \cdot a_{1}}{-S O A}=a_{1} \\
& \neq T P
\end{aligned}
$$

e:

$$
T P=\frac{a_{0}}{Y_{t+1}}+a_{1}=-\frac{a_{0}{ }^{\prime}}{a_{2}} \frac{1}{Y_{t+1}}-\frac{a_{1}{ }^{\prime}}{a_{2}}
$$


APENNDICE C - PREVISÓES DOS MODELOS DE TRADE-OFF E PECKING ORDER(SEGUNDO FAMA E FRENCH, 2002)

\section{MODELO DE TRADE-OFF}

Custos de Bancarrota:

1. As firmas mais lucrativas possuem mais dívida valor contábil.

2. As firmas com lucros mais voláteis têm menos dívida valor contábil.

Taxas: [Miller (1977), Miller e Scholes (1978), De Angelo e Masulis (1980)].

1. As firmas com expectativas de maiores impostos a pagar (firmas mais lucrativas e firmas com lucros menos voláteis) possuem mais dívida contábil.

2. Controlando para lucratividade, as firmas com mais nondebt tax shields (Exemplo: depreciação e gastos em pesquisa e desenvolvimento) têm menos dívida contábil.

Problemas de agência criados pelo caixa livre [Jensen e Meckling (1976), Easterbrook (1984), Jensen (1986)].

As previsões são conduzidas pelos benefícios de dividendos e dívida em controlar o problema de agência criado pelo caixa livre (lucro menos investimentos).

1. Controlando para oportunidades de investimento, as firmas com maiores lucratividades pagam mais dividendos e são mais endividadas.

2. Controlando para lucratividade, firmas com mais investimentos lucrativos pagam menos dividendos e se endividam menos. 
3. Dividendos e dívida são substitutos como mitigadores do problema de agência criado pelo caixa livre e a relação entre dividendos e dívida é negativa.

Problemas de agência (custos de investimento insuficiente e investimento exagerado) entre acionistas e credores [Fama e Miller (1972), Jensen e Meckling (1976), Myers (1977)].

1. Firmas com maiores expectativas de investimentos têm menos dívida corrente.

\section{MODELO DA PECKING ORDER}

Neste modelo as principais imperfeições de mercado são os custos financeiros e assimetria informacional, os quais crescem à medida que investimentos são financiados com ativos arriscados ou emitindo novas ações.

1. Controlando para oportunidades de investimento, as firmas mais lucrativas distribuem maior quantia em dividendos e possuem menos dívida contábil.

2. Controlando para lucratividade, as firmas com mais investimentos correntes e esperados distribuem menos quantia em dividendos e possuem mais dívida contábil.

3. Segundo a simples versão do modelo, dada a lucratividade, as firmas que mais investem possuem maior dívida contábil.

4. Segundo uma visão mais complexa do modelo, as empresas que possuem maior volatilidade em seu fluxo de caixa livre distribuem menos dividendos e possuem menos dívida contábil. Firmas com maior expectativa de investimentos possuem menos dívida corrente. A relação entre a distribuição de dividendos das empresas e seu nível de dívida é negativa.

5. Dividendos são estáveis, deixando variações de curto prazo em investimentos e lucratividade serem absorvidas por variações em dívida. 
APÊNDICE D - REGRESSÕES VIA PAINEL COM DUMMIES ANUAIS

TABELA DI - ESTIMATIVAS DA EQUAÇÃO (4.3) DE DETERMINAÇÃO DOS DIVIDENDOS POR PAINEL

\begin{tabular}{|c|c|c|c|c|c|c|c|c|c|}
\hline & \multirow[b]{2}{*}{ Int } & \multirow[b]{2}{*}{$Y_{t+1} / A_{t+1}$} & \multicolumn{5}{|c|}{$Y_{t+1} / A_{t+1}^{*}$} & \multirow[b]{2}{*}{$\mathrm{TP}$} & \multirow[b]{2}{*}{$\mathrm{R}^{2}$} \\
\hline & & & $V_{t} / A_{t}$ & $E_{t} / A_{t}$ & $\operatorname{LN}\left(A_{t}\right)$ & $\mathrm{TL}_{\mathrm{t}+1}$ & $d A_{t} / A_{t}$ & & \\
\hline \multicolumn{10}{|l|}{ Painel B } \\
\hline Coeficiente & 0.011 & 0.537 & 0.026 & 0.482 & -0.034 & & -0.011 & 0.08 & 0.26 \\
\hline Estatística t & $(5.92)$ & $(3.12)$ & $(0.63)$ & $(3.22)$ & $(-2.76)$ & & $(-2.88)$ & & \\
\hline \multicolumn{10}{|l|}{ Painel A } \\
\hline Coeficiente & 0.008 & 1.015 & 0.382 & 0.121 & -0.034 & -1.277 & -0.033 & 0.11 & 0,39 \\
\hline Estatística t & $(4.27)$ & $(6.07)$ & $(6.13)$ & $(1.02)$ & $(-4.12)$ & $(-6.30)$ & $(-6.60)$ & & \\
\hline \multicolumn{10}{|l|}{ Painel C } \\
\hline Coeficiente & 0.008 & 1.041 & 0.417 & & -0.032 & -1.426 & -0.034 & 0.11 & 0,38 \\
\hline Estatística t & $(4.25)$ & $(5.91)$ & $(5.74)$ & & $(-4.33)$ & $(-6.45)$ & $(-6.37)$ & & \\
\hline
\end{tabular}

A variável dependente é $D_{t+1} / A_{t+1}$, ou seja, dividendos para o ano fiscal $t+1$ dividido pelo ativo total valor contábil em $t+1$. A tabela reporta os coeficientes da eq. (4.3) estimados por painel com dummies anuais (omitidas) para minimizar a correlação seccional e suas estatísticas t. A variável $\mathrm{Y}_{\mathrm{t}+1}$ é lucro líquido para o ano $\mathrm{t}+\mathrm{l}$. $\mathrm{V}_{\mathrm{t}}$ é o valor de mercado do Ativo Total representado pela soma do valor de mercado das açóes e passivo total para o ano $t, \mathrm{E}_{\mathrm{t}}$ é o lucro antes do imposto de renda para o ano $t, \mathrm{TL}_{\mathrm{t}+1}$ é a meta de alavancagem para $t+1 . \mathrm{O} \mathrm{R}^{2}$ foi ajustado pelos graus de liberdade. E TP é média temporal de $\mathrm{a}_{1}+\mathrm{a}_{1 \mathrm{~V}}$ $\operatorname{Mn}\left(V_{t} / A_{t}\right)+a_{1 L} \operatorname{Mn}\left(E_{t} / A_{t}\right)+a_{1 S} \operatorname{Mn}\left(\ln \left(A_{t}\right)\right)+a_{1 D} \operatorname{Mn}\left(T_{t+1}\right)+a_{1 A} \operatorname{Mn}\left(d A_{t} / A_{t}\right)$, onde $\mathrm{Mn}$ ( ) são as médias seccionais das variáveis por ano e os a's são os coeficientes da equação(4.3). 


\section{TABELA D2 - ESTIMATIVAS DA EQUAÇÃO (5.3) DE AJUSTAMENTO} DOS DIVIDENDOS POR PAINEL

\begin{tabular}{lccccccc}
\hline & Int & $\mathrm{Y}_{\mathrm{t}+1} / \mathrm{A}_{\mathrm{t}+1}$ & $\mathrm{D}_{\mathrm{t}} / \mathrm{A}_{\mathrm{t}+1}$ & $\mathrm{~d} \mathrm{~A}_{\mathrm{t}+1} / \mathrm{A}_{\mathrm{t}+1}$ & $\mathrm{SOA}$ & $\mathrm{TP}$ & $\mathrm{R}^{2}$ \\
\hline Coeficiente & 0.007 & 0.088 & -0.685 & -0.002 & 0,68 & 0,13 & 0,52 \\
Estatística t & $(4.34)$ & $(5.26)$ & $(-7.94)$ & $(-3.46)$ & & & \\
\hline
\end{tabular}

A variável dependente é $\left(\mathrm{D}_{\mathrm{t}+1}-\mathrm{D}_{\mathrm{t}}\right) / \mathrm{A}_{\mathrm{t}+1}$. A tabela reporta os coeficientes da eq. (5.3) estimados por painel com dummies anuais (omitidas) para minimizar a correlação seccional e suas estatísticas $t$. A variável $\mathrm{Y}_{\mathrm{t}+1}$ é lucro líquido para o ano $t+1$. $\mathrm{D}_{\mathrm{t}}$ é o valor dos dividendos para o ano $t, \mathrm{dA}_{\mathrm{t}+1}$ é a diferença entre os ativos totais do ano $t+l$ e $t$. A velocidade de ajustamento, SOA, é igual a menos o coeficiente de inclinação em $\mathrm{D}_{\mathrm{t}} / \mathrm{A}_{\mathrm{t}+1}$. E TP é a inclinação de $\mathrm{Y}_{\mathrm{t}+1} / \mathrm{A}_{\mathrm{t}+1}$ dividido por $\mathrm{SOA}$ (ver apêndice $\mathrm{B}$ ). $O \mathrm{R}^{2}$ foi ajustado pelos graus de liberdade.

\section{TABELA D3 - ESTIMATIVAS DA EQUAÇÃO (5.4) DE AJUSTAMENTO DOS DIVIDENDOS POR PAINEL}

\begin{tabular}{lccccccc}
\hline & Int & $\mathrm{Y}_{\mathrm{t}+1} / \mathrm{A}_{\mathrm{t}+1}$ & $\mathrm{D}_{\mathrm{t}} / \mathrm{A}_{\mathrm{t}+1}$ & $\mathrm{~d} \mathrm{~A}_{\mathrm{t}+1} / \mathrm{A}_{\mathrm{t}+1}$ & $\mathrm{SOA}$ & $\mathrm{TP}$ & $\mathrm{R}^{2}$ \\
\hline Média & 0,004 & 0,123 & $-0,670$ & $-0,002$ & 0,67 & 0,18 & 0,61 \\
Estatística t & $(2,67)$ & $(24,56)$ & $(-20,83)$ & $(-1,78)$ & & & \\
\hline
\end{tabular}

A variável dependente é $\left(D_{t+1}-D_{t}\right) / A_{t+1}$. A tabela reporta os coeficientes da eq. (5.4) estimados por painel com dummies anuais (omitidas) para minimizar a correlação seccional e suas estatísticas $t$. A variável $Y_{t+1}$ é lucro líquido para o ano $t+1$. $D_{t}$ é o valor dos dividendos para o ano $t, \mathrm{~d} \mathrm{~A}_{\mathrm{t}+1}$ é a diferença entre os ativos totais do ano $t+l \mathrm{e} t$. A velocidade de ajustamento, SOA, é igual a menos o coeficiente de inclinação em $\mathrm{D}_{t} / \mathrm{A}_{\mathrm{t}+1}$. E TP é a média da inclinação em $Y_{t+1} / A_{t+1}$ dividido por SOA. O coeficiente de inclinação em $Y_{t+1} /$ $A_{t+1}$ é a média temporal de $a_{1}+a_{1 V} \operatorname{Mn}\left(V_{t} / A_{t}\right)+a_{1 L} \operatorname{Mn}\left(E_{t} / A_{t}\right)+a_{1 S} \operatorname{Mn}\left(\ln \left(A_{t}\right)\right)+a_{1 D}$ $\operatorname{Mn}\left(\mathrm{L}_{\mathrm{t}+1}\right)+\mathrm{a}_{1 \mathrm{~A}} \operatorname{Mn}\left(\mathrm{d} \mathrm{A}_{\mathrm{t}} / \mathrm{A}_{\mathrm{t}}\right)$, onde $\operatorname{Mn}()$ são as médias seccionais das variáveis por ano $\mathrm{e}$ os $a_{1}$ 's são os coeficientes da eq. (5.4). A inclinação em $D_{t} / A_{t+1}$ é a média temporal de $a_{2}+$ $a_{2 V} \operatorname{Mn}\left(V_{t} / A_{t}\right)+a_{2 L} M n\left(E_{t} / A_{t}\right)+a_{2 S} M n\left(\ln \left(A_{t}\right)\right)+a_{2 D} M n\left(L_{t+1}\right)+a_{2 A} M n\left(d A_{t} / A_{t}\right)$, onde $\operatorname{Mn}\left(\right.$ ) são as médias seccionais das variáveis por ano e os $\mathrm{a}_{2}$ 's são os coeficientes da equação(5.4). $\mathrm{O} \mathrm{R}^{2}$ foi ajustado pelos graus de liberdade. 
TABELA D4 - ESTIMATIVAS DA EQUAÇÃO (6.1) DE DETERMINAÇÃO DA ALAVANCAGEM DOS DIVIDENDOS POR PAINEL

\begin{tabular}{|c|c|c|c|c|c|c|c|}
\hline & Int & $V_{t} / A_{t}$ & $E T_{t} / A_{t}$ & $\operatorname{LN}\left(A_{t}\right)$ & $d A_{t} / A_{t}$ & $\mathrm{TP}_{\mathrm{t}+1}$ & $\mathrm{R}^{2}$ \\
\hline \multicolumn{8}{|l|}{ Painel A } \\
\hline Média & 0.900 & 0.244 & -0.743 & -0.032 & 0.002 & & 0,20 \\
\hline Estatística t & (9.58) & $(6.36)$ & $(-5.37)$ & $(-5.05)$ & (3.28) & & \\
\hline \multicolumn{8}{|l|}{ Painel B } \\
\hline Média & 0.897 & 0.244 & -0.743 & -0.032 & 0.002 & -0.002 & 0,21 \\
\hline Estatística t & (9.55) & $(6.35)$ & $(-5.36)$ & $(-5.03)$ & (3.31) & $(-0.63)$ & \\
\hline \multicolumn{8}{|l|}{ Painel C } \\
\hline Média & 0,892 & 0,217 & & $-0,035$ & $-0,001$ & $-0,002$ & 0,17 \\
\hline Estatística t & $(9,42)$ & $(6,14)$ & & $(-5,30)$ & $(-1,86)$ & $(-0,49)$ & \\
\hline
\end{tabular}

A variável dependente é $\mathrm{L}_{\mathrm{t}+\mathrm{l}} / \mathrm{A}_{\mathrm{t}+\mathrm{l}} \cdot \mathrm{L}_{\mathrm{t}+1}=\left(\mathrm{ELP}_{\mathrm{t}+1}+\mathrm{PC}_{\mathrm{t}+1}\right)$ é o valor contábil do passivo total, ou seja, é a soma do Exigível de Longo Prazo e Passivo Circulante no ano $t+1$ A tabela reporta os coeficientes da eq. (6.1) estimados pela por painel com dummies anuais (omitidas) para minimizar a correlação seccional e suas estatísticas $t$. $\mathrm{V}_{\mathrm{t}}$ é o valor de mercado do Ativo Total representado pela soma do valor de mercado das açóes e passivo total para o ano $t, E_{t}$ é o lucro operacional próprio para o ano t. $\mathrm{ETP}_{\mathrm{t}+\mathrm{l}}$ é $\mathrm{a}_{1}+\mathrm{a}_{1 \mathrm{~V}} \mathrm{Mn}\left(\mathrm{V}_{\mathrm{t}} / \mathrm{A}_{\mathrm{t}}\right)+$ $a_{1 L} \operatorname{Mn}\left(E_{t} / A_{t}\right)+a_{1 S} \operatorname{Mn}\left(\ln \left(A_{t}\right)\right)+a_{1 A} \operatorname{Mn}\left(d_{A} / A_{t}\right)$, onde os as são os coeficientes da equação $(4.3)$ por painel. $\mathrm{O} \mathrm{R}^{2}$ foi ajustado pelos graus de liberdade. 
TABELA D5 - ESTIMATIVA DA EQUAÇÃO (7.1) DE AJUSTAMENTO DA DÍVIDA POR PAINEL

\begin{tabular}{lcccccc}
\hline & Int & $\mathrm{TL}_{\mathrm{t}+1}$ & $\mathrm{~L}_{\mathrm{t}} / \mathrm{A}_{\mathrm{t}}$ & $\mathrm{dE}_{\mathrm{t}+1} / \mathrm{A}_{\mathrm{t}+1}$ & $\mathrm{dA} \mathrm{A}_{\mathrm{t}+1} / \mathrm{A}_{\mathrm{t}+1}$ & $\mathrm{R}^{2}$ \\
\hline Painel A & & & & & & \\
Média & 0,069 & 0,124 & $-0,206$ & $-0,171$ & 0,010 & 0,15 \\
Estatística t & $(1,35)$ & $(1,99)$ & $(-3,24)$ & $(-2,12)$ & $(3,15)$ & \\
\hline
\end{tabular}

A variável dependente é $\mathrm{L}_{\mathrm{t}+1} / \mathrm{A}_{\mathrm{t}+1} \cdot-\mathrm{L}_{\mathrm{t}} / \mathrm{A}_{\mathrm{t}} \cdot \mathrm{L}_{\mathrm{t}+1}=\left(\mathrm{ELP}_{\mathrm{t}+1}+\mathrm{PC}_{\mathrm{t}+1}\right)$ é o valor contábil do passivo total, ou seja, é a soma do Exigível de Longo Prazo e Passivo Circulante no ano $\mathrm{t}+\mathrm{l}$. A tabela reporta os coeficientes da eq. (7.1) estimados por painel com dummies anuais (omitidas) para minimizar a correlação seccional e suas estatísticas t. $\mathrm{TL}_{\mathrm{t}+1}$ é o valor esti-

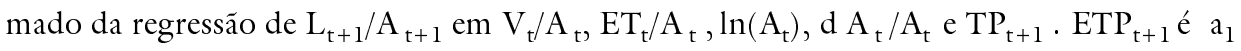
$+a_{1 V}\left(V_{t} / A_{t}\right)+a_{1 L}\left(E_{t} / A_{t}\right)+a_{1 S}\left(\ln \left(A_{t}\right)\right)+a_{1 A}\left(d A_{t} / A_{t}\right)$, onde os a's são os coeficientes da equação forma reduzida da equação (4.3). $\mathrm{O} \mathrm{R}^{2}$ foi ajustado pelos graus de liberdade.

Agradecemos a Caio Ibsen Almeida (Faculdades Ibmec/RJ), Daniel Ferreira (Stockholm School of Economics), Mônica R. Lima (Faculdades Ibmec/RJ), Ricardo Rochman (EAESP/FGV) e demais participantes do $3^{\circ}$ Encontro Brasileiro de Finanças pelos valiosos comentários e sugestôes. As imprecisões remanescentes são de nossa responsabilidade. Endereçar correspondência a Ricardo D. Brito: ricardodob@ibmec.br.

(Recebido em outubro de 2003. Aceito para publicação em julho de 2004). 